\title{
Remodeling the host environment: modulation of the gastric epithelium by the Helicobacter pylori vacuolating toxin (VacA)
}

\section{Ik-Jung Kim and Steven R. Blanke*}

Department of Microbiology, Institute for Genomic Biology, University of Illinois, Urbana, IL, USA

\section{Edited by:}

D. Scott Merrell, Uniformed

Services University, USA

\section{Reviewed by:}

Richard Peek, Vanderbilt University

Medical Center, USA

Timothy Cover, Vanderbilt University

School of Medicine, USA

*Correspondence:

Steven R. Blanke, Department of Microbiology, Institute for Genomic Biology, University of Illinois, 302A Burrill Hall, 601 S. Goodwin Ave.,

Urbana, IL 61801, USA.

e-mail:sblanke@illinois.edu

\begin{abstract}
Virulence mechanisms underlying Helicobacter pylori persistence and disease remain poorly understood, in part, because the factors underlying disease risk are multifactorial and complex. Among the bacterial factors that contribute to the cumulative pathophysiology associated with $\mathrm{H}$. pylori infections, the vacuolating cytotoxin (VacA) is one of the most important. Analogous to a number of $H$. pylori genes, the vacA gene exhibits allelic mosaicism, and human epidemiological studies have revealed that several families of toxin alleles are predictive of more severe disease. Animal model studies suggest that VacA may contribute to pathogenesis in several ways. VacA functions as an intracellular-acting protein exotoxin. However, VacA does not fit the current prototype of $A B$ intracellular-acting bacterial toxins, which elaborate modulatory effects through the action of an enzymatic domain translocated inside host cells. Rather, VacA may represent an alternative prototype for $A B$ intracellular acting toxins that modulate cellular homeostasis by forming ion-conducting intracellular membrane channels. Although VacA seems to form channels in several different membranes, one of the most important target sites is the mitochondrial inner membrane. VacA apparently take advantage of an unusual intracellular trafficking pathway to mitochondria, where the toxin is imported and depolarizes the inner membrane to disrupt mitochondrial dynamics and cellular energy homeostasis as a mechanism for engaging the apoptotic machinery within host cells. VacA remodeling of the gastric environment appears to be fine-tuned through the action of the Type IV effector protein CagA which, in part, limits the cytotoxic effects of VacA in cells colonized by $H$. pylori.
\end{abstract}

Keywords: Helicobacter pylori, VacA, vacuolation, mitochondria, apoptosis

\section{Helicobacter pylori AND VacA}

Virulence mechanisms underlying Helicobacter pylori-mediated gastric maladies have remained enigmatic, in part, because disease risk is multifactorial and complex (Compare et al., 2010; Polk and Peek, 2010). However, several bacterial factors clearly contribute to the pathophysiology associated with $H$. pylori infections (Fischer et al., 2009), and one of the most important is the vacuolating cytotoxin (VacA) (Cover and Blanke, 2005).

Since the discovery of VacA nearly 25 years ago as the proteinacious factor within $H$. pylori culture filtrates that intoxicates epithelial cells and induces vacuole biogenesis (Leunk et al., 1988), the study of this toxin has been challenging in part, because the toxin possesses a number of surprising and unusual characteristics that don't fit neatly into current concepts of bacterial toxins. Nonetheless, several interesting and important properties of VacA have become apparent. First, the gene encoding VacA (vacA) is characterized by a high degree of genetic variation; strains with specific allelic variants of vacA that exhibit greater levels of VacAmediated cytotoxic activity in vitro are associated with a greater risk of gastric disease in $\mathrm{H}$. pylori-infected humans. Moreover, experimental evidence supports the idea that VacA may promote
$H$. pylori colonization, persistence, and infection-associated disease pathophysiology.

\section{STRUCTURAL PROPERTIES OF VacA}

H. pylori synthesize VacA as an approximately $140 \mathrm{kDa}$ preprotoxin (Figure 1), which undergoes sequential proteolytic processing during Type Va secretion as an auto-transporter protein (Fischer et al., 2001). The secreted mature form of VacA is a $88 \mathrm{kDa}$ monomer (Cover and Blaser, 1992), that is purified from H. pylori growth medium (Gonzalez-Rivera et al., 2010) as watersoluble hexameric or heptameric rings (Figure 1) in single or bilayered structures (Figure 1) (Lupetti et al., 1996; Cover et al., 1997; Lanzavecchia et al., 1998; Czajkowsky et al., 1999; Adrian et al., 2002; El-Bez et al., 2005). Acidic or alkaline pH promotes dissociation of VacA oligomeric complexes into monomers (Cover et al., 1997; Molinari et al., 1997; Yahiro et al., 1997), which is likely the form of the toxin to bind host cells during infection (Gonzalez-Rivera et al., 2010).

The mature $88 \mathrm{kDa}$ form of the toxin is sometimes detected as a proteolytically-nicked protein, comprising two domains designated p33 (residues 1-311) and p55 (residues 312-821), that 


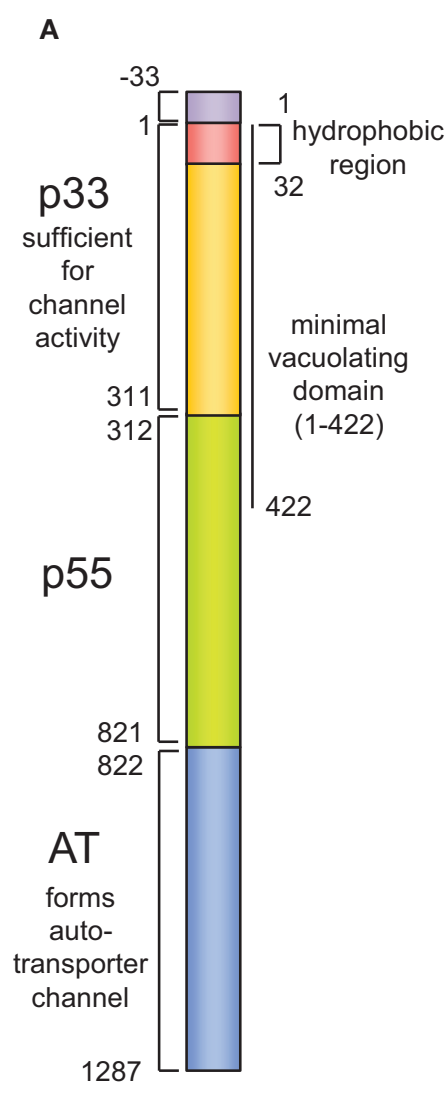

B
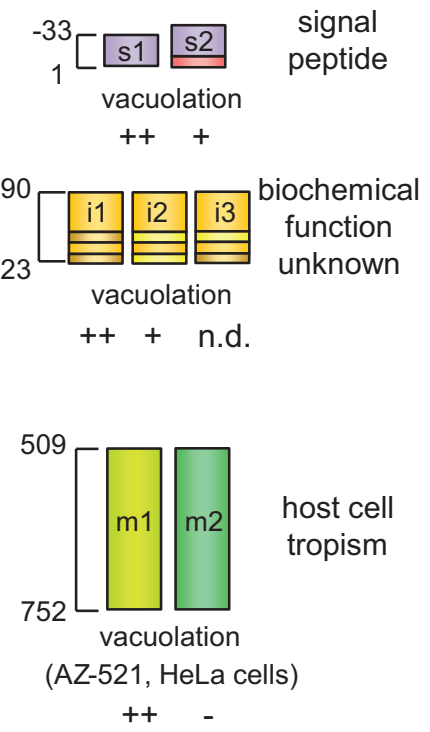

c top view
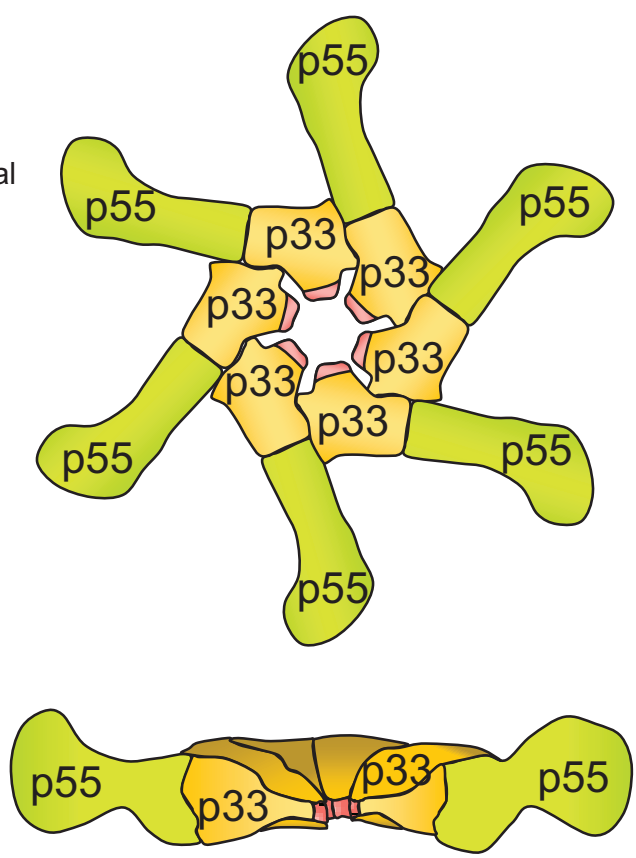

side/cross-sectional view
FIGURE 1 | VacA structure. (A) Schematic VacA structure. Each domain is denoted by a different color and by the first and last amino residue of that particular domain. The name of each domain is denoted in bold, and its function (if known) is described. (B) The polymorphic nature of the vacA gene is emphasized by highlighting the three major allele families, which are remain non-covalently associated (Figure 1A) (Telford et al., 1994; Cover et al., 1997; Ye et al., 1999; Nguyen et al., 2001; Willhite et al., 2002; Torres et al., 2004, 2005). Recently, a crystal has been solved for p55 (Gangwer et al., 2007), revealing a predominantly right-handed parallel beta-helix structure, which is typical for autotransporter passenger domains. High-resolution structural data for p33 are not yet available. Proteolytic cleavage into discrete functional domains is a characteristic of a number of so-called intracellular-acting AB toxins (Blanke, 2005). However, proteolytic cleavage of VacA into p33 and p55 is apparently not required for VacA activity (Burroni et al., 1998). While neither p33 nor p55 alone are sufficient to induce vacuole biogenesis, the cellular activity of VacA can be reconstituted from two separate recombinant proteins added exogenously (Gonzalez-Rivera et al., 2010) or expressed ectopically within cultured cells (Ye et al., 1999; Ye and Blanke, 2000; Willhite et al., 2002; Ye and Blanke, 2002). All of p33 and approximately the amino-terminal 100 residues of p55 are apparently required to induce vacuolation, revealed when a fragment comprising VacA residues 1-422, but not a fragment comprising residues 1-394, induced cellular vacuolation when expressed in transiently transfected cells (de Bernard et al., 1997, 1998; Ye et al., 1999). located in the signal region (s region), the intermediate region (i region), and the mid-region (m region). (C) The proposed structure of the VacA oligomeric assembly, based on the crystal structure of a portion of p55 [Gangwer et al. (2007)] and electron microscopy imaging of VacA oligomers [El-Bez et al. (2005)].
The association of p33 or p55 with discrete toxin functions remains poorly understood. Several lines of evidence suggest that p55 possesses a domain important for binding the toxin to the cell surface (Pagliaccia et al., 1998; Reyrat et al., 1999; Wang and Wang, 2000; Wang et al., 2001). However, the binding of p55 to cells appears to be considerably weaker than that of fulllength VacA. Moreover, p33 appears to also contribute to VacA cell surface binding (Torres et al., 2005; Gonzalez-Rivera et al., 2010).

The amino-terminal 34 residues of $\mathrm{p} 33$ domain comprise what is predicted to be a highly hydrophobic domain, which has been implicated to be critical for the capacity of VacA to form ionconducting channels (Vinion-Dubiel et al., 1999; Ye and Blanke, 2000; McClain et al., 2003). As discussed below, VacA channels are probably the biochemical activity most critical for the cellular modulating activity of the toxin. However, deletion of part of this region (residues 1-27) resulted in a mutant form of VacA that also demonstrated some channel activity in planar lipid bilayers, albeit requiring a significantly longer time to for channel formation (Vinion-Dubiel et al., 1999), suggesting that the hydrophobic amino-terminus is not absolutely required for VacA channel activity. More recently, channel activity in planar lipid 
bilayers was also demonstrated for a mutant form of p33 lacking residues 1-37 (Domanska et al., 2010). Thus, the molecular basis underlying VacA channel formation, at least in artificial lipid bilayers, remains to be clarified.

\section{INTRACELLULAR MEMBRANE CHANNEL FORMATION BY VacA: THE TRUE BIOCHEMICAL ACTIVITY OF VacA?}

Analogous to many other bacterial toxins, VacA is able to insert into membranes and form ion-conducting channels (Czajkowsky et al., 1999, 2005; Tombola et al., 1999a,b, 2001b). Characterization of VacA channels has revealed slight anion selectivity (Czajkowsky et al., 1999; Iwamoto et al., 1999; Tombola et al., 1999a,b, 2001b) and several electrophysiological properties that are similar to some anion-selective channels found in human cells (Campello et al., 2002; Czajkowsky et al., 2005). Electron microscopy images of membrane-associated VacA have revealed primarily hexagonal ring-shaped structures (Czajkowsky et al., 1999; Adrian et al., 2002; Geisse et al., 2004) that likely correspond to VacA channels or a pre-channel form of the toxin, although direct evidence is lacking for both of these possibilities. Based on studies indicating that both VacA binding to lipid membranes (Czajkowsky et al., 1999) and channel formation (Czajkowsky et al., 1999; Iwamoto et al., 1999; Geisse et al., 2004) are enhanced by acid-activation of the toxin support a model that VacA binds to the membrane surface as a monomer, and subsequently undergoes assembly into higher-ordered structures and membrane insertion.

VacA channel activity has been associated with a number of the toxin's cellular modulatory effects. The exact nature of cell modulation is apparently dependent on the site of channel formation. The release of cellular ions and small organic molecules has been attributed to VacA channel formation at the plasma membrane (Szabo et al., 1999; Tombola et al., 2001a). Cellular vacuolation is been ascribed to VacA channels within endocytic compartments (Montecucco and Rappuoli, 2001). VacA channel formation within the inner membranes of mitochondria (Galmiche et al., 2000; Willhite and Blanke, 2004; Calore et al., 2010; Domanska et al., 2010) is believed to be the biochemical activity of the toxin responsible for depolarization of the inner membrane (Kimura et al., 1999; Willhite and Blanke, 2004) and disruption of mitochondrial dynamics, ultimately responsible for inducing cell death (Jain et al., 2011).

\section{THE RELATIONSHIP BETWEEN vacA GENETIC DIVERSITY AND DISEASE}

Understanding the importance of VacA for $H$. pylori-mediated disease is not as straightforward as demonstrating the correlation between the presence or absence of the vacA gene in human isolates and the incidence of gastric disease. Indeed, the very earliest studies revealed that the vacA gene is present in essentially all human isolates. Further study revealed in short order that not all $v a c A$ genes are identical.

\section{THE ALLELIC DIVERSITY OF vacA}

Although essentially all $H$. pylori strains carried a vacA gene, the levels of vacuolating activity with bacterial culture filtrates were found to be markedly different from strain to strain (Leunk et al.,
1988; Figura et al., 1989; Cover et al., 1990, 1993; Cover and Blaser, 1992). Several reasons underlying the diversity in vacuolating activity among $H$. pylori strains were discovered. $H$. pylori isolates were identified that carried non-sense mutations, internal duplications, deletions, or $1 \mathrm{bp}$ insertions within the vacA gene (Ito et al., 1998). Differences in the transcription of $v a c A$ or the efficiency in VacA secretion have also been found to influence the levels of vacuolating activity with $H$. pylori culture filtrates (Forsyth et al., 1998). Perhaps the most important reason, however, for differences in vacuolating activity between differences in strains is variation discovered in the VacA amino acid sequences (Atherton et al., 1995), which subsequently have been associated with the observed divergence in cellular vacuolating activity (Figure 1A) (Atherton et al., 1995; Strobel et al., 1998; van Doorn et al., 1998). The vacA genotype is recognized as an important determinant of the toxin' cellular activity.

The maximum amount of sequence diversity is found in several defined regions of vacA (Figure 1A). The middle of $v a c A$, which was named the "m (for middle) region," encodes an approximately 800 bp region in the carboxyl-terminal p55 domain of VacA. Within the $\mathrm{m}$ region, the two primary allelic families that are differentiated among strains are called $\mathrm{m} 1$ and m2 (Atherton et al., 1995, 1999; Pagliaccia et al., 1998; Ji et al., 2002). Sequence diversity within the m-alleles of vacA has been functionally associated with differences in cell tropism between VacA proteins (Pagliaccia et al., 1998; Ji et al., 2000; Wang et al., 2001). There is some evidence to indicate that the differences in cell type specificities demonstrated for the $\mathrm{s} 1 / \mathrm{m} 1$ and $\mathrm{s} 1 / \mathrm{m} 2$ forms of VacA may be due to, at least in part to distinct cell binding properties (Pagliaccia et al., 1998; Ji et al., 2000; Wang et al., 2001). The VacA determinants that influence the cell-type specificities demonstrated for the $\mathrm{m} 1$ and $\mathrm{m} 2$ forms of VacA have been mapped to a 148-residue region within p55 (Ji et al., 2000; Skibinski et al., 2006). However, the entire m-region is apparently essential for cell surface binding and vacuolating activity of the toxin (Wang and Wang, 2000; Skibinski et al., 2006).

The amino-terminal end of VacA, designated as the "s region," also demonstrates considerable sequence diversity, which extends from the signal sequence that directs secretion across the bacterial inner membrane into the amino terminus of the processed mature toxin (Figure 1A) (Atherton et al., 1995; Strobel et al., 1998; van Doorn et al., 1998). The two primary allelic groups that have been differentiated among strains are referred to as s1 and s2, and the s1 group further differentiates into the sla, s1b, and s1c subtypes. Notably, sequence differences between strains carrying the s1 or s2 alleles correspond directly to functional differences, as strains carrying the s2 vacA allele fail to induce cellular vacuolation (Atherton et al., 1995). Analysis of s2 forms of vacA revealed that the signal sequences of these proteins are processed at a different cite, resulting in a mature form of VacA with a 12 amino acid extension that inactivates the toxin (Letley and Atherton, 2000; McClain et al., 2001; Letley et al., 2003).

Most recently, a third region of sequence diversity, called the " $i$ (for intermediate) region" has been identified in the carboxylterminal half of $\mathrm{p} 33$ between the $\mathrm{s}$ and $\mathrm{m}$ regions of VacA (Rhead et al., 2007). Three primary i-region types (i1, i2, and i3) (Chung et al., 2010) have been identified and revealed to be associated 
with the divergent vacuolating activities associated with different forms of the toxin. Although the structure-function relationships underlying the contributions of the i-region to the cellular activity of VacA have not been identified, il vacA strains were found to have the strongest vacuolating activity on mammalian cells. The i region has been proposed to be a more reliable predictor of severe gastric disease than the s- or m-regions of the vacA gene, and il strains are strongly associated with gastric adenocarcinoma and peptic ulcer disease (Rhead et al., 2007; Basso et al., 2008).

\section{THE ASSOCIATION OF vacA GENOTYPES WITH DISEASE}

Efforts to evaluate potential roles of VacA in the pathogenesis of human gastroduodenal diseases are complicated by the multifactorial nature of $H$. pylori pathophysiology in the human stomach. Nonetheless, epidemiology studies have been extremely useful for demonstrating a correlation between particular vacA i-, m-, and s-region allelic types and occurrence and severity of disease in $H$. pylori-infected humans. Many studies have provided evidence for a higher association of disease in individuals infected with $H$. pylori strains possessing s1 vacA alleles encoding toxin variants with greater cellular activity in vitro than strains with s2 vacA alleles (Atherton et al., 1995, 1997; Han et al., 1998; Rudi et al., 1998; Strobel et al., 1998; van Doorn et al., 1998, 1999; Gerhard et al., 1999; Kidd et al., 1999; de Gusmao et al., 2000). In addition, strains with s1 alleles are a higher risk for gastric carcinoma than strains harboring vacA s2 alleles (Miehlke et al., 2000; Ashour et al., 2002; Figueiredo et al., 2002). As far as the $\mathrm{m}$ region, $H$. pylori strains harboring $\mathrm{ml}$ vacA alleles have been more highly associated with gastric carcinoma (Miehlke et al., 2000; Ashour et al., 2002; Figueiredo et al., 2002), as well as gastric alterations that normally precede the onset of gastric cancer, including epithelial damage, atrophic gastritis, and intestinal metaplasia (Atherton et al., 1997; Nogueira et al., 2001), than are those strains with $\mathrm{m} 2$ vacA alleles. Strains carrying both the s1 (Atherton et al., 1995; Rudi et al., 1998; Vinion-Dubiel et al., 1999; Ye and Blanke, 2000) and the $\mathrm{ml}$ allele (Pagliaccia et al., 1998; Ji et al., 2000; Letley et al., 2003; Skibinski et al., 2006), are strongly associated with increased bacterial load and PMN infiltration within human gastric mucosa (Hofman et al., 2007), duodenal and gastric ulceration (Atherton et al., 1995, 1997; Rudi et al., 1998; Strobel et al., 1998; Figueiredo et al., 2001) and gastric cancer (Basso et al., 1998; Evans et al., 1998; Kidd et al., 1999; Miehlke et al., 2000; Figueiredo et al., 2001). As discussed above, more recent studies have suggested the possibility that the identity of the i allele may be the most reliable predictor of severity of disease, with the il allele predictive of the most severe disease outcome (Rhead et al., 2007).

\section{PROPERTIES OF VACA RELATED TO H. pylori COLONIZATION AND DISEASE}

$H$. pylori have co-evolved along with humans, and thus the use of existing rodent and non-human primate models for studying bacterial colonization and gastric disease would be predicted to have limitations. Nonetheless, animal studies have been valuable for revealing that VacA may contribute to $H$. pylori pathogenesis in several ways. Administration of purified toxin within a mouse model induces the degeneration of the gastric mucosa, inflammatory cell recruitment, and the formation of gastric lesions resembling the pathology observed in humans (Telford et al., 1994; Ghiara et al., 1995; Marchetti et al., 1995; Fujikawa et al., 2003). VacA has been implicated as a contributing factor within a Mongolian gerbil disease model (Ogura et al., 2000). VacA promotes $H$. pylori colonization within a mouse infection model (Salama et al., 2001). More recently, several studies suggested that VacA may contribute to $H$. pylori subversion of the host's immune response through elaboration of several immunosuppressive activities (Montecucco and de Bernard, 2003; Fischer et al., 2004). An enormous body of work supports the importance of VacA in $H$. pylori-mediated human disease. In contrast, the molecular and cellular basis by which VacA interacts with and modulates human cells remains poorly understood.

\section{VacA AS A CELLULAR MODULATOR: THE MULTIPLE CONSEQUENCES OF VacA INTOXICATION}

In an effort to understand how VacA contributes to H. pylori colonization of the stomach and development of gastroduodenal disease, the effects of VacA on human cells have been investigated in vitro. VacA is able to intoxicate a wide range of cell types, including gastric epithelial cells and several types of immune cells, resulting in an array of multiple different cellular alterations (Figure 2).

The published modulatory effects of VacA on epithelial and immune cells will be discussed briefly. In contrast, recent evidence implicating VacA as a mitochondrial-targeting toxin will be considered in more detail.

\section{VacA MODULATION OF EPITHELIAL CELL FUNCTION}

The first documented (Leunk et al., 1988; Smoot et al., 1996; Pagliaccia et al., 1998) cellular activity of VacA was the capacity to induce the biogenesis of large intracellular vacuoles that occupy almost the entire epinuclear region (Figure 2B). VacAmediated vacuolar compartments are acidic (Cover et al., 1991), enriched in the small GTPase Rab7 as well as other late endocytic markers (Papini et al., 1994, 1996, 1997; Molinari et al., 1997; Li et al., 2004), and exclude trypan blue (Leunk et al., 1988), indicating that vacuolation per se is not a cytolethal response to VacA intoxication. Vacuolation may be due to toxin-mediated alterations in the trafficking of endocytic vesicles, as indicated by VacA-dependent inhibition of the intracellular degradation of epidermal growth factor, and inhibition of procathepsin D maturation (Satin et al., 1997).

The capacity of VacA to form anion-conducting channels is important for the biogenesis of vacuoles (Szabo et al., 1999; Tombola et al., 1999b; Vinion-Dubiel et al., 1999; Ye and Blanke, 2000; McClain et al., 2003; Genisset et al., 2007), which then swell further in the presence of membrane permeable weak bases (Czajkowsky et al., 1999; Szabo et al., 1999; Tombola et al., 1999b; Morbiato et al., 2001). The sources of membrane required for the formation of the large intracellular vacuoles remains unclear. The demonstration that the SNARE protein syntaxin 7, which is involved in intracellular membrane fusion events, is localized to the membranes of VacA-induced vacuoles supports a model that VacA-induced vacuoles may result from the fusion of multiple smaller endocytic compartments (Gauthier et al., 


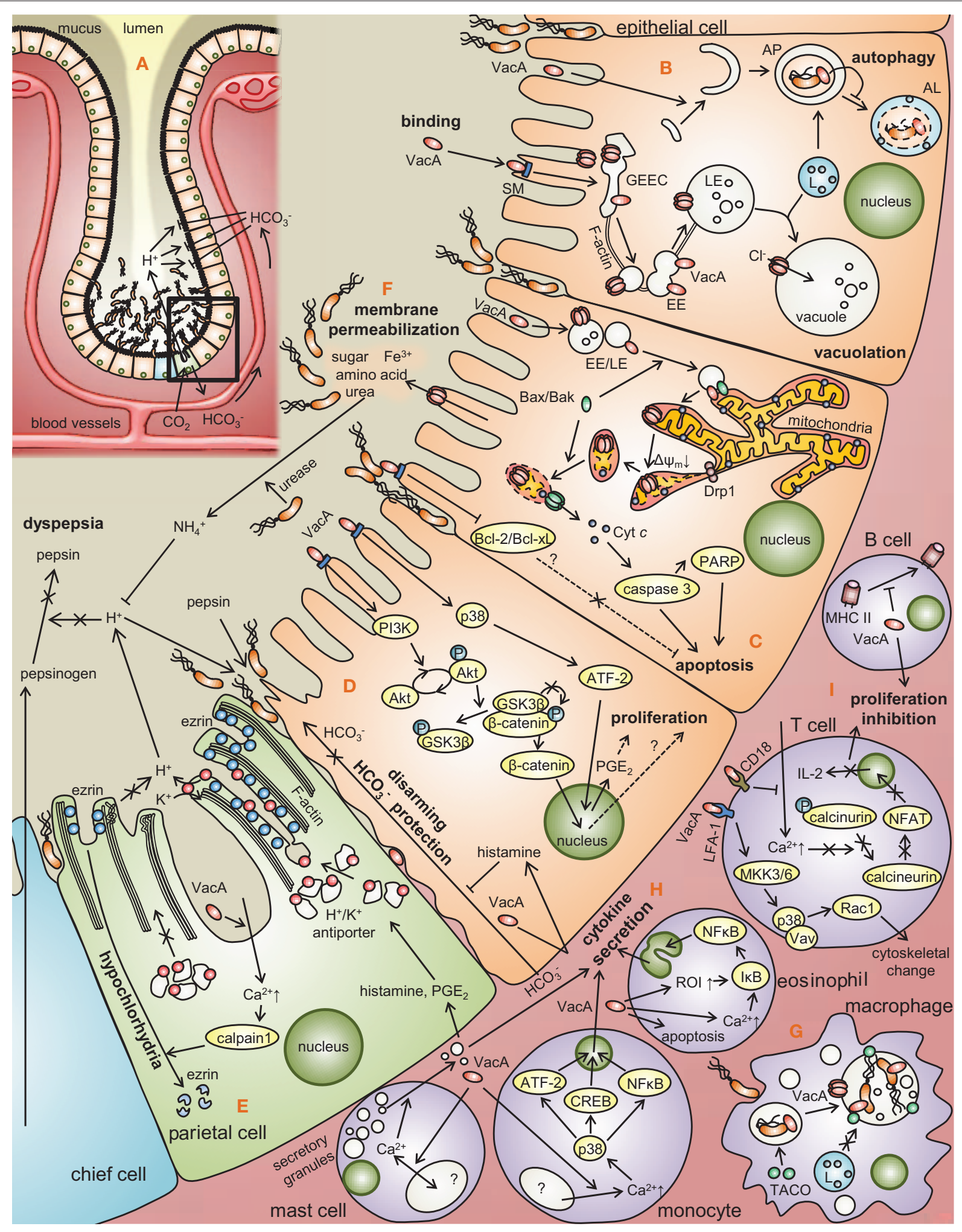

FIGURE 2 | Modulation of gastric cell functions by VacA. (A) Distribution of $\mathrm{H}$. pylori at the gastric epithelium. Approximately $80 \%$ of $H$. pylori localize to the layer of mucus overlaying the epithelial membrane, while the remainder attach to the membrane surface as microcolonies. (B) VacA binds to epithelial cell surface receptors (SM, RPTP-a/ $\beta$ ), and is taken up by a
Cdc42-dependent, pinocytic-like mechanism into (GPI)-enriched early endosomal compartments (GEECs) followed by F-actin-dependent transport to early and late endosomal compartments (EE and LE). LE fusion with lysosomes (L) promotes vacuole biogenesis in a manner dependent on VacA (Continued) 


\begin{abstract}
FIGURE 2 | Continued
channel activity. VacA was recently reported to induce the formation of autophagosomes (AP), which typically mature to autophagolysosomes (AL). (C) A portion of VacA-containing EEs/LEs are transported to mitochondria within Bax-enriched vesicles. VacA channel formation within the

mitochondrial inner membrane induces depolarization, $\Delta \Psi \mathrm{m}$ dissipation, and disruption of mitochondrial dynamics at the level of Drp1-dependent fission, triggering Bax permeabilization of the mitochondrial outer membrane and cytochrome $c$ release, resulting in apoptosis. VacA-mediated downregulation of Bcl-2/Bcl-xL [Matsumoto et al. (2011)] also promotes cell death. (D) VacA has been proposed to promote cellular proliferation via p38 activation, which increases ATF-2 regulated expression of prostaglandin E2 $\left(\mathrm{PGE}_{2}\right)$ [Hisatsune et al. (2007)], as well as the activation of $\beta$-catenin though the deregulation of phosphorylation of glycogen synthase kinase 3 (GSK3 $\beta$ ) and Akt, initiated by the activation of phosphoinositide 3-kinase (PI3K) [Nakayama et al. (2009)]. Histamine secretion stimulated by VacA inhibits $\mathrm{HCO}_{3}{ }^{-}$mediated protection against acid and pepsin [Tuo et al. (2009)]. (E) VacA induces the influx of $\mathrm{Ca}^{2+}$ into parietal cells, thereby activating calpain 1, a protease that degrades ezrin, an actin binding protein that is critical for proton release [Wang et al. (2008)], thereby deregulating acid secretion machinery within parietal cells in a manner that may promote $H$. pylori persistence. (F) VacA channel formation in the apical membrane surface may expose $H$. pylori to diffusible nutrients
\end{abstract}

such as amino acids, sugar, and metal ions [Szabo et al. (1999); Debellis et al. (2001); Montecucco and Rappuoli (2001); Tombola et al. (2001a)]. H. pylori urease may convert released urea into ammonia which neutralizes acid, which inhibits activation of pepsinogen to pepsin, eventually causing dyspepsia [Mobley et al. (1995); Carter et al. (2009)]. (G) VacA-dependent remodeling of $\mathrm{H}$. pylori-containing vacuoles facilitates bacterial survival within macrophages [Zheng and Jones (2003)]. (H) VacA stimulates the release of secretory granules within mast cell by causing the oscillation of intracellular $\mathrm{Ca}^{2+}$ levels [de Bernard et al. (2005)]. VacA intoxication of monocytes results in $\mathrm{Ca}^{2+}$-dependent p38 activation, leading to proinflammatory cytokine production via ATF-2, CREB, and NF- $\kappa$ B-dependent mechanisms [Hisatsune et al. (2008)]. Within eosinophils, VacA deregulates ROS intermediates (ROI) and intracellular $\mathrm{Ca}^{2+}$ to stimulate proinflammatory cytokine release by a NF- $\kappa$ B-dependent mechanism [Kim et al. (2007)]. (I) In T cells, VacA recognized by $\mathrm{CD} 18$, blocks $\mathrm{Ca}^{2+}$ influx, the activation of calcineurin, and nuclear factor of activated T-cells (NFAT) a transcription factor required for the expression of interleukin-2 (IL-2), ultimately suppressing T-cell proliferation [Sewald et al. (2008)]. VacA recognized by lymphocyte function-associated antigen 1 (LFA-1) receptor activates mitogen-activated protein kinase kinase $3 / 6$ (MKK3/6), leading to the activation of p38 and Rac 1, resulting in the cytoskeletal change [Sewald et al. (2008)]. In B cells, VacA disrupts antigen presentation of $\mathrm{MHC}$ II.
2007). Conversely, several other studies instead support a model of swelling of the internal membranes of the late endosomal compartments (de Bernard et al., 2002; Genisset et al., 2007).

Despite intensive study into the molecular basis and mechanism underlying vacuole biogenesis in VacA intoxicated cells, it remains poorly understood whether vacuolation per se directly contributes to $H$. pylori colonization, persistence or disease pathophysiology. Alternatively, vacuolation may represent the general stress response of cells intoxicated with VacA.

\section{Modulatory effects of VacA on cell viability}

Sustained infection with $H$. pylori results in alterations within in the gastric mucosa that have been associated with the progression of infection to gastric disease. As mentioned above, VacA alone is sufficient to damage the gastric mucosa of mice (Telford et al., 1994; Ghiara et al., 1995; Marchetti et al., 1995; Fujikawa et al., 2003). A hallmark of $H$. pylori infection is increased level of apoptosis in human gastric mucosa (Mannick et al., 1996; Moss et al., 1996; Jones et al., 1997; Wagner et al., 1997; Fan et al., 1998), mice (Jones et al., 2002), and Mongolian gerbil models (Peek et al., 2000).

Increased cell death within the epithelial membrane may contribute to $H$. pylori disease pathogenesis in several ways (Correa and Houghton, 2007). Increased apoptosis may alter the gastric environment to promote $H$. pylori persistence (Cover and Blanke, 2005), while at the same time, contribute to gastric disease, including peptic ulcers and gastric adenocarcinoma (Cover and Blaser, 2009). Although several H. pylori factors (Peek et al., 1999; Kawahara et al., 2001) have been implicated as mediators of cell death, VacA is per se sufficient to induce cell death (Figure 2C) (Boquet et al., 2003; Cover et al., 2003). VacA-mediated cell death is apparently complex, involving cellular alterations that are consistent with both apoptotic (Kuck et al., 2001; Boquet et al., 2003; Cover et al., 2003; Willhite et al., 2003; Oldani et al., 2009) and necrotic (Willhite and Blanke, 2004; Radin et al., 2011) cell death programs.

\section{Modulatory effects of VacA on signaling transduction pathways regulating cellular homeostasis}

VacA-mediated cellular vacuolation is typically observed within several hours after addition of VacA to cells. However, VacA causes several cellular effects that can be detected at much earlier time points. Within $10 \mathrm{~min}$ after addition of VacA to a human gastric adenocarcinoma cell line (AZ-521), two classes of mitogen-activated protein (MAP) kinases (p38 and ERK1/2) and the activating transcription factor 2 (ATF-2) signaling pathway were reported to be activated (Figure 2D) (Nakayama et al., 2004; Hisatsune et al., 2007). An inhibitor of p38 kinase activity (SB203580) does not block VacA-induced vacuolation or VacAinduced cytochrome $c$ release, which indicates that VacA-induced activation of the p38/ATF-2 signal pathway is independent of VacA effects on late endocytic compartments and mitochondria (Nakayama et al., 2004). One reported consequence of VacA-induced p38 activation is upregulation of cyclooxygenase-2 (COX-2) expression, leading to increased $\mathrm{PGE}_{2}$ production (Figure 2D) (Hisatsune et al., 2007). In addition to effects of VacA on MAP kinases, VacA is reported to activate a signaling pathway involving tyrosine phosphorylation of the G proteincoupled receptor kinase interactor (Git1) (Fujikawa et al., 2003) and a signaling pathway that leads to upregulated expression of vascular endothelial growth factor (Caputo et al., 2003).

In contrast to effects of VacA on endocytic compartments and mitochondria, the relatively rapid cellular responses to VacA described above are likely to be the consequences of VacA interactions with specific cell surface components, without a requirement for internalization of the toxin. The cell surface receptors for VacA that are involved in activating MAP kinase signaling pathways have not yet been characterized. Activation of the Git1 pathway is dependent on VacA binding to RPTP- $\beta$ (Fujikawa et al., 2003). VacA-induced upregulation of vascular endothelial growth factor reportedly occurs through a pathway involving activation of epidermal growth factor receptor, MAP kinases, and COX-2 (Caputo et al., 2003). 


\section{Modulatory effects of VacA on epithelial monolayer permeability/nutrient acquisition}

VacA has been reported to lower the trans-epithelial electric resistance (TER) of monolayers formed by several different types of polarized epithelial cells, an effect that is attributable to increased paracellular epithelial permeability of the monolayers to low molecular mass molecules and ions (Figure 2F) (Papini et al., 1997). Selective permeabilization of epithelial monolayers by VacA has been proposed to support the growth of $H$. pylori in the gastric mucus layer by promoting the release of factors such as $\mathrm{Fe}^{3+}, \mathrm{Ni}^{2+}$, sugars, and amino acids (Papini et al., 1997). The mechanisms by which VacA alters paracellular permeability are not yet well understood. This activity does not require acidactivation of purified oligomeric VacA, and is not inhibited by bafilomycin A1.

VacA also been reported to increase the transepithelial flux of certain molecules, including urea and bicarbonate (Figure 2E) (Guarino et al., 1998; Szabo et al., 1999; Debellis et al., 2001; Tombola et al., 2001a). Transepithelial flux of these molecules is attributed to the formation of VacA channels in the plasma membrane (Szabo et al., 1999). Bicarbonate release has been suggested to promote bacterial survival within the acidic gastric mucus layer, and release of urea may optimize the enzymatic activity of $H$. pylori urease. Most recently, VacA has been demonstrated to cause mislocalization of the transferrin receptor to the apical membrane of polarized monolayers, thereby facilitating iron acquisition from interstitial holotransferrin to H. pylori microcolonies attached to the apical membrane (Tan et al., 2011).

\section{Modulatory effects of VacA on the cytoskeleton}

VacA-mediated cytoskeletal alterations in both actin filaments and the microtubule system have been reported (Ashorn et al., 2000; Pai et al., 2000; Tabel et al., 2003; Yuan et al., 2004; Hennig et al., 2005; Wang et al., 2005). Studies emerging from a yeast two-hybrid screen suggested that, at least in this system, VacA interacted with an intermediate filament interacting protein (de Bernard et al., 2000). Moreover, VacA may alter the expression of multiple cytoskeletal-related genes (Pai et al., 2000; Yuan et al., 2004; Wang et al., 2005), although the mechanisms underlying these cytoskeletal alterations have not been demonstrated.

More recently, VacA intoxication of parietal cells was reported to prevent the recruitment of $\mathrm{H}, \mathrm{K}$-ATPase-containing tubulovesicles to the apical membrane (Figure 2E), thereby disrupting apical membrane-cytoskeletal interactions (Wang et al., 2008). The disruption in the radial arrangement of actin filaments in apical microvilli was found to be due to the loss of ezrin integrity. The authors proposed that the proteolysis of ezrin in VacAinfected parietal cells represents a novel mechanism underlying $H$. pylori-induced inhibition of acid secretion, thereby resulting in hypochlorhydria.

\section{Modulatory effects of VacA in promoting intracellular survival of H. pylori in gastric epithelial cells}

The importance of an intracellular reservoir of $H$. pylori during persistent gastric infection has been debated. While there is now consensus that $H$. pylori are found primarily in the mucus layer overlying gastric epithelial cells within humans, with the remainder on the apical surface of the epithelial membrane, there is evidence that the bacteria might occasionally localize within gastric epithelial cells. Several studies have suggested that VacA might promote survival of $H$. pylori within gastric epithelial cells (Bjorkholm et al., 2000; Petersen et al., 2001). VacA was shown to promote intracellular survival of $H$. pylori via a mechanism involving VacA-dependent retention of Rab7, fusion of late endocytic compartments, and sequestration H. pylori-containing cell compartments away from the lysosomal degradative pathway (Terebiznik et al., 2006). In contrast, another study did not detect a role of VacA in intracellular survival of H. pylori (Amieva et al., 2002).

\section{Modulatory effects of VacA resulting in the induction of autophagy}

Recently, VacA was demonstrated to induce autophagic signaling within intoxicated epithelial cells (Figure 2B) (Terebiznik et al., 2009; Raju et al., 2012). The autophagic vesicles and vacuoles induced within VacA intoxicated cells are apparently not the same vesicles. While the role of autophagy during $H$. pylori infection is currently unclear, autophagy might function to limit the toxin-mediated cellular cytotoxicity (Terebiznik et al., 2009).

\section{VacA AS A MODULATOR OF IMMUNE CELL FUNCTION}

Beyond the well-documented effects of VacA on epithelial cells, additional roles for the toxin in modulating the properties of $\mathrm{T}$ lymphocytes have been demonstrated (Figure 2H) (Boncristiano et al., 2003; Gebert et al., 2003; Sundrud et al., 2004; OswaldRichter et al., 2006; Algood et al., 2007). VacA inhibits Jurkat $\mathrm{T}$ cell production of interleukin 2 (IL-2), which promotes $\mathrm{T}$ cell viability and proliferation, as well as down-regulates surface expression of the IL-2 receptor (Boncristiano et al., 2003; Gebert et al., 2003; Sundrud et al., 2004), by inhibiting activation of nuclear factor of T cells (NFAT) (Boncristiano et al., 2003; Gebert et al., 2003), a transcriptional regulator required for optimal $\mathrm{T}$ cell activation. VacA inhibits NFAT activation by a mechanism involving the blocking of calcium influx into cells from the extracellular milieu, thereby inhibiting the activity of the $\mathrm{Ca}^{2+}$ calmodulin-dependent phosphatase calcineurin (an enzyme that dephosphorylates NFAT) (Boncristiano et al., 2003; Gebert et al., 2003).

In contrast to what was reported for Jurkat T cells VacA intoxication primary human CD $4+\mathrm{T}$ cells inhibited the proliferation of activated cells, induced mitochondrial depolarization, ATP depletion, and cell cycle arrest (Sundrud et al., 2004; Oswald-Richter et al., 2006). Moreover, VacA also inhibits activation-induced proliferation of human CD8 + T cells and B cells (Torres et al., 2007). The immunomodulatory actions of VacA on T- and Blymphocytes suggest the possibility that VacA might contribute to the ability of $H$. pylori to establish a persistent infection in the human gastric mucosa.

Interestingly, the effects of VacA on T cells may occur via more than one mechanism. While some effects are dependent on the formation of VacA channels in cell membranes (Boncristiano et al., 2003; Sundrud et al., 2004; Oswald-Richter et al., 2006), others are the result of activation of intracellular signaling in $\mathrm{T}$ cells, via a channel-independent mechanism (Boncristiano et al., 2003). It is hypothesized that VacA enters the lamina propria via 
disruptions in the gastric epithelial layer, and thereby intoxicates $\mathrm{T}$ cells and various other types of immune cells. In addition, it is possible that VacA may target intraepithelial $\mathrm{T}$ lymphocytes. Most of the effects of VacA on T lymphocytes described above are expected to result in localized immunosuppression. VacA also stimulates expression of COX-2, a proinflammatory enzyme, in $\mathrm{T}$ lymphocytes, which is expected to have a proinflammatory effect (Boncristiano et al., 2003). Thus, the effects of VacA on immune cells are complex, and are characterized by both immunostimulatory and immunosuppressive actions.

\section{MODULATORY EFFECTS OF VacA ON ANTIGEN PRESENTATION}

VacA has been reported to interfere with the process of antigen presentation by B lymphocytes (Figure 2I). In one model system, VacA interfered with proteolytic processing of tetanus toxoid and inhibited the invariant chain (Ii)-dependent pathway of antigen presentation mediated by newly synthesized major histocompatibility complex (MHC) class II molecules (Molinari et al., 1998). This effect of VacA on antigen-presenting cells is likely due to VacA-induced effects on endocytic compartments, resulting in alterations in endocytic trafficking.

\section{MODULATORY EFFECTS OF VacA ON ANTIGEN MACROPHAGES}

Two reports provided evidence that VacA contributes to the formation of large vesicular compartments (termed megasomes) in $H$. pylori-infected macrophages by stimulating homotypic phagosome fusion (Allen et al., 2000; Zheng and Jones, 2003). VacA stimulates the recruitment and retention of the tryptophan aspartate-containing coat protein (TACO or coronin 1) to phagosomes, thereby disrupting proper vesicular maturation (Zheng and Jones, 2003), which in turn, may impair phagocytic killing of $H$. pylori. Notably, one report did not detect any effects of VacA on phagosome formation or intracellular survival of $H$. pylori in human monocytes (Rittig et al., 2003). In addition to having effects on vesicular compartments in macrophages, VacA also is reported to stimulate activation of p38 MAP kinase and cause increased expression of COX-2 in macrophages (Boncristiano et al., 2003). Finally, it has been reported that VacA may contribute to the apoptosis of macrophages infected with H. pylori (Menaker et al., 2004).

\section{MODULATORY EFFECTS OF VacA ON MAST CELLS, EOSINOPHILS, AND NEUTROPHILS}

Incubation of VacA with mast cells stimulates production of pro-inflammatory cytokines and induces mast cell chemotaxis (Figure 2G) (Supajatura et al., 2002; de Bernard et al., 2004). Binding of VacA to a mast cell line (RBL-2H3 cells) induces an oscillation in levels of cytosolic calcium and exocytosis of secretory granules (de Bernard et al., 2004). The rapid changes in calcium concentration that follow VacA interaction with mast cells may result from VacA interactions with cell surface receptors and activation of specific signal transduction pathways, without a requirement for membrane channel formation.

VacA is reported to have an effect on eosinophils, manifested as upregulated expression of chemokines (Figure 2G) (Kim et al., 2007). This effect is reported to occur via a pathway involving calcium influx, mitochondrial generation of reactive oxygen intermediates, and NF- $\kappa$ B activation (Kim et al., 2007). VacA also is reported to have effects on neutrophils, including activation of p38 MAP kinase and increased expression of COX-2 (Boncristiano et al., 2003; Brest et al., 2006).

\section{TARGETING THE POWER SOURCE: VacA AS A MITOCHONDRIAL-ACTING TOXIN}

One of the most intriguing and highly studied activities associated with VacA over the past 10 years, is the capacity of the toxin to target and modulate the properties of mitochondria within host cells (Figure 2C). In addition to the well-known role of mitochondria in central metabolism, this organelle has emerged as a central hub of regulation for many of the most fundamental cellular processes, including programmed cell death, progression of the cell cycle, and innate immune sensing. At the same time, it is now clear that a loss of mitochondrial function, or dysfunction, has been associated with perhaps hundreds of human diseases and disorders. However, the extent to which mitochondrial function is altered during infection of host cells with pathogenic microbes as well as the possible consequences of pathogen-mediated mitochondrial dysfunction, are both poorly understood. This is a particularly relevant issue because several dozen pathogenic bacteria and viruses have been reported to generate protein effectors that localize to mitochondria (Blanke, 2005).

\section{MITOCHONDRIAL DYSFUNCTION IS A CHARACTERISTIC OF VacA CELLULAR INTOXICATION}

VacA-mediated modulation of mitochondrial function was first reported approximately a decade after the toxin was discovered as the factor within $H$. pylori culture filtrates that induces vacuolation within cultured epithelial cell lines (Leunk et al., 1988). VacA intoxication of human gastric epithelial AZ-521 cells was reported to induce mitochondrial dysfunction (Figure 2C), as manifested by a drop in cellular ATP levels, mitochondrial transmembrane potential $\left(\Delta \Psi_{m}\right)$, and oxygen consumption (Kimura et al., 1999). Since this first report, VacA-dependent alterations in mitochondria, and in particular $\Delta \Psi_{m}$ dissipation, have been confirmed independently by several groups (Galmiche et al., 2000; Willhite and Blanke, 2004; Yamasaki et al., 2006; Calore et al., 2010; Domanska et al., 2010; Foo et al., 2010), and are considered as one of the primary consequences of toxin activity at mitochondria (Blanke, 2005; Galmiche and Rassow, 2010; Rassow, 2011).

\section{CONSEQUENCES OF VacA-DEPENDENT MITOCHONDRIAL DYSFUNCTION}

Because of the central importance of mitochondria in cellular metabolism, it is perhaps not be surprising that VacA-mediated mitochondrial dysfunction has distinct consequence for host cells. In general, mitochondrial health is dependent on the functional integrity of the organelle's inner and outer membranes, which have distinct biochemical and functional properties. Increased permeability can result in depolarization of the mitochondrial inner membrane, leading to $\Delta \Psi_{m}$ dissipation and a loss of metabolism (Figure 2C), which as indicated above, occurs characteristically within VacA intoxicated cells (Galmiche 
et al., 2000; Willhite and Blanke, 2004; Yamasaki et al., 2006; Calore et al., 2010; Domanska et al., 2010; Foo et al., 2010). Increased outer membrane permeability (MOMP) results in the release of pro-apoptotic protein effectors from the inner membrane space into the cytosol (Blanke, 2005). Several studies have reported the release of mitochondrial cytochrome $c$ within cells intoxicated with VacA (Galmiche et al., 2000; Willhite et al., 2003, 2004; Yamasaki et al., 2006), resulting in apoptotic cell death, which has been demonstrated to be a consequence of VacA intoxication (Smoot et al., 1996; Kuck et al., 2001; Cover et al., 2003).

\section{WHERE IN THE CELL DOES VacA ACT TO INDUCE MITOCHONDRIAL DYSFUNCTION?}

\section{The case for VacA as a mitochondrial-targeting toxin}

VacA-mediated changes in mitochondrial properties could result as an indirect consequence of vacuole formation, or potentially from VacA action at the cell surface. However, the discovery that the amino-terminal p33 domain (but not the carboxyl-terminal p55 domain) of VacA localized to mitochondria when expressed ectopically within mammalian cells suggested a different possibility, that at least the p33 fragment might be hardwired to localize to mitochondria from the cytosol of mammalian cells (Galmiche et al., 2000).

Several groups have now demonstrated that subsequent to uptake into epithelial cells, full-length VacA toxin from $H$. pylori partially localizes to mitochondria, as shown by both fluorescence imaging and biochemical fractionation (Willhite and Blanke, 2004; Yamasaki et al., 2006; Oldani et al., 2009). The importance of VacA mitochondrial localization for toxin dependent cell death has been questioned based on the observation that a large fraction of VacA remains associated with endocytic compartments (Yamasaki et al., 2006). However, disrupting VacA intracellular trafficking with the actin-disrupting agent cytochalasin D prevented VacA localization to mitochondria, as well as toxin-dependent $\Delta \Psi_{m}$ dissipation and cell death (Willhite and Blanke, 2004; Oldani et al., 2009). Likewise, in cells transfected with CagA, VacA was prevented from trafficking to mitochondria, and VacA intoxicated cells were protected from toxin-dependent apoptosis, further supporting the idea that VacA exerts its biochemical activity directly at mitochondria (Willhite and Blanke, 2004; Oldani et al., 2009).

\section{An inside job? VacA localizes to the mitochondrial inner membrane}

When p33 was expressed as a fusion with GFP within transiently transfected mammalian cell lines, ultrastructural immunocytochemistry studies using transmission electron microscopy provided images showing that a substantial fraction of the fusion protein clearly localizes in the interior of mitochondria (Galmiche et al., 2000). Perhaps more convincing have been studies using isolated mitochondria, which have demonstrated that VacA is imported beyond the outer membrane, but probably not past the inner membrane (Galmiche et al., 2000; Domanska et al., 2010; Foo et al., 2010). Together, these studies support a model that the site of action of VacA is the mitochondrial inner membrane.

\section{Turning off the power: how does VacA cause mitochondrial dysfunction?}

The exact mechanism by which VacA induces mitochondrial dysfunction remains to be determined. Several studies have indicated that mutant forms of VacA with disrupted membrane channel activity are attenuated in their capacity to induce $\Delta \Psi_{m}$ dissipation, as well as cytochrome $c$ release and other downstream changes associated with apoptosis within intact cells (Figure 2C) (Willhite and Blanke, 2004) or isolated mitochondria (Yamasaki et al., 2006). In studies conducted with intact cells, mutant forms of VacA with point mutations (P9A, G14A) that attenuated channel activity were taken into cells and localized to mitochondria (Willhite and Blanke, 2004). These data strongly support a model that subsequent to mitochondrial import, VacA inserts into the mitochondrial inner membrane and forms ion-conducting channels to cause membrane depolarization, resulting in $\Delta \Psi_{m}$ dissipation and a loss in ATP production. Many aspects of this model remain to be evaluated, including the intriguing question of how VacA channels at mitochondria alone might result in what appears to be widespread $\Delta \Psi_{m}$ dissipation throughout the cell. It also remains to be seen whether or not VacA recognizes and/or interacts with a mitochondrial-specific protein or lipid localized to the mitochondrial inner membrane to facilitate membrane insertion and channel formation.

\section{Break-in: how does VacA breach the mitochondrial outer membrane}

While some $\mathrm{AB}$ toxins possess the remarkable ability to translocate an active fragment across host cell membranes, there is no indication that VacA facilitates its own entry past the mitochondrial outer membrane and ultimately to the inner membrane. Rather, recent work (Domanska et al., 2010) suggests that VacA translocation across mitochondrial outer membranes may require toxin-exploitation of existing and highly conserved protein import machinery. Studies with isolated mitochondria revealed that the mitochondrial import receptor Tom20 is involved in the uptake of $\mathrm{p} 33$, potentially reflecting the capacity of Tom 20 to interact with the hydrophobic residues of precursor proteins (Abe et al., 2000). Subsequent transport of p33 across the mitochondrial outer membrane was found to be mediated by the general import pore formed by Tom 40 .

\section{HOW DOES INTRACELLULAR VacA TARGET MITOCHONDRIA? Does VacA mimic endogenous proteins destined for mitochondrial import?}

Mitochondria-localized proteins are generally hardwired with targeting sequences embedded within their amino-acid sequences. However, VacA does not possess an easily identifiable mitochondrial-targeting motif. Fluorescence imaging studies revealed that when expressed as GFP fusions in transiently transfected cells, p33, but not p55, localized to mitochondria (Galmiche et al., 2000). The sufficiency of the amino-terminal p33 domain for mitochondrial localization within cells has been confirmed independently (Domanska et al., 2010).

However, the molecular basis by which VacA targets mitochondria appears to be complex. One study showed that that neither 
the first 100 nor 200 amino-terminal residues were sufficient to target a amino-terminally fused green fluorescence protein (GFP) expressed ectopically or microinjected into the cytosol of cells to intracellular mitochondria (Galmiche et al., 2000). On the other hand, another study showed that the amino-terminal 34 residues, comprising a highly hydrophobic sub-domain, is sufficient to promote mitochondrial localization when expressed ectopically as a fusion-protein with carboxyl-terminal GFP (Domanska et al., 2010). The reasons underlying the differences between these two studies are unclear, but may originate in the different orientation of the GFP fusion proteins between the two studies.

\section{AN ALTERNATIVE MODEL FOR VacA LOCALIZATION TO MITOCHONDRIA DOES VacA ENTER THE CYTOSOL DURING INTRACELLULAR TRANSPORT?}

The earliest studies to define the molecular basis of VacA localization to mitochondria employed fragments or mutant forms of the toxin either microinjected or expressed within the cytosol of transiently transfected cells (Galmiche et al., 2000). These approaches are clearly useful for interrogating VacA within the cytosol. Nonetheless, there is a lack of experimental evidence for cytosolic VacA within cells exposed to exogenous toxin. One of the earliest papers to consider the intracellular trafficking of VacA (Garner and Cover, 1996) reported VacA, as detected by indirect immunofluorescence microscopy, located in a perinuclear region, but not associated with cytotoxin-induced vacuoles, although later studies using higher resolution techniques indicated that VacA is in fact detectable in vacuoles (Li et al., 2004).

Subsequent studies of intracellular trafficking revealed VacA within small punctate vesicles just after uptake from the cell surface (Gauthier et al., 2004, 2005, 2007; Gupta et al., 2008, 2010) and at later time points, localized to epinuclear structures confirmed to be mitochondria (Willhite and Blanke, 2004; Oldani et al., 2009). Although it can be perilous to base a model partially on "negative data," the lack of evidence that VacA enters the cytosolic compartment after uptake from the cell surface suggests that VacA cellular activity does not require either VacA or a fragment of VacA to be first translocated to the cytosol.

\section{The unusual intracellular routing of VacA}

If the intracellular action of VacA indeed does not require the toxin to become cytosolic, then other mechanisms must be considered to explain localization of the toxin to mitochondria subsequent to cellular uptake. One alternative mechanism could conceivably depend the transport of VacA-containing membranebound compartments from the cell surface to mitochondria. To our knowledge, a well-defined pathway for the transport of any component from the cell surface to mitochondria has not been defined.

Studies of VacA intracellular transport have failed thus far to produce evidence that VacA exploits either the acidic environment of late endosomal compartments or the ERAD pathway to target mitochondria. Instead, work over the past decade has indicated that VacA is taken up and trafficked by an unusual pinocytic mechanism that had not previously been described for other intracellular acting bacterial exotoxins (Figure 2B).
Specifically, VacA is internalized into epithelial cell lines by a Cdc42-dependent pinocytic mechanism, and is trafficked to late endosomal/lysosomal compartments (Molinari et al., 1997; Papini et al., 1997; McClain et al., 2000; Gauthier et al., 2004, 2005, 2007). As the first step during cellular intoxication, VacA binds to the plasma membrane of sensitive cells (Garner and Cover, 1996), analogous to other intracellular-acting bacterial toxins (Blanke, 2005). Recently, sphingomyelin (SM) has been identified as a plasma membrane receptor that confers cellular sensitivity to VacA by binding the toxin to the cell surface (Gupta et al., 2008). Moreover, VacA-SM interactions were demonstrated to be required for Cdc42-dependent pinocytic uptake from the plasma membrane and trafficking of VacA (Gupta et al., 2010).

\section{What is the molecular GPS for VacA localization to mitochondria?}

The relationship between VacA intracellular trafficking and mitochondrial localization remains poorly understood. It is tempting to speculate that the unusual aspects of VacA uptake and transport from the cell surface specifically promote, and perhaps are even required for toxin transport to cellular mitochondria, although this idea remains to be formally tested. One recent study implicated the pro-death, multi-domain $\mathrm{Bcl}-2$ proteins $\mathrm{Bax}$ and Bak, as essential for the intracellular positioning of VacAcontaining endocytic compartments in close juxtaposition with mitochondria (Figure 2C) (Calore et al., 2010). In the absence of Bax/Bak, VacA-containing vesicles were not observed to localize with mitochondria. Likewise, vesicles coated with Bax or Bak were not observed to be associated with mitochondria in cells unless the cells had been intoxicated with VacA. This was an unexpected observation, as neither Bax nor Bak were previously considered to have a functional role in endocytic vesicle trafficking.

Bax/Bak was previously reported to be important for VacAmediated cell death (Yamasaki et al., 2006), but these new findings suggest a potentially expanded and novel role for these two molecules in the targeting and/or docking of VacA-containing transport vesicles with mitochondria. The exact mechanisms by which Bax/Bak induce the spatial juxtaposition of VacAcontaining endosomal compartments with mitochondria, or the possible contributions of either of these two endogenous effectors to VacA translocation to the mitochondrial inner membrane are potentially exciting areas of future enquiry. One intriguing possibility is that Bax and Bak promote membrane fusion between mitochondria and the VacA-containing vesicles, allowing VacA to localize to the inner membrane without having to dissociate from one membrane to insert into a second membrane. However, such a scenario has not yet been tested.

\section{MITOCHONDRIAL TARGETING AND EPITHELIAL REMODELING BY VacA}

The issue of why VacA targets mitochondria remains an intriguing question. The multiple important roles of mitochondria for cellular function suggest that VacA-dependent alterations in mitochondria would have consequences for gastric epithelial cells. As discussed above, an increase in apoptotic cells within the gastric epithelium is a hallmark of persistent $H$. pylori infection, and 
VacA has been demonstrated to be essential and sufficient among H. pylori factors for inducing cell death. But is VacA action at mitochondria linked to cell death?

Recent studies have provided new insights into how VacA action at mitochondria might be functionally associated with cell death. VacA was demonstrated to disrupt mitochondrial dynamics (Figure 2C) (Jain et al., 2011), which is the cellular balance between mitochondrial fission and fusion, the two processes that together control mitochondrial morphology, quality control, and energy transduction. VacA-mediated disruption of mitochondrial dynamics required hyperactivation of dynamin-related protein 1 (Drp1), which is a master regulator of mitochondrial fission, and Drp1 activation, in turn, was essential for activation of Bax, thereby committing VacA intoxicated cells to undergoing apoptosis. Thus, the discovery of VacA-mediated activation of Drp1 provides the direct molecular link between VacA action at mitochondria and toxin-dependent cell death.

The mechanism by which VacA induces Drp1 is not clear. VacA-mediated dissipation of mitochondrial transmembrane potential $\left(\Delta \Psi_{m}\right)$ may induce Drp1 activation indirectly, as mitochondrial depolarization has previously been shown in unrelated studies to induce calcineurin-mediated dephosphorylation of Drp1 as a mechanism to drive Drp1 translocation to mitochondria (Cereghetti et al., 2008). On the other hand, the possibility that VacA may act more directly to activate Drpl cannot currently be ruled out.

\section{FINE-TUNING THE HOST PATHOGEN INTERFACE: SYNERGISTIC AND ANTAGONISTIC ASSOCIATIONS BETWEEN THE VacA EXOTOXIN AND CagA, THE TYPE IV EFFECTOR OF H. pylori}

Bacterial toxins are most typically studied as purified proteins in order to best tease out their specific contributions to modulation of host cell function. While often appropriate, these approaches do not take into account possible functional interactions that may exist between virulence factors. CagA is an important $H$. pylori virulence factor, and analogous to vacA, specific cagA alleles are highly predictive for the incidence and severity of disease associated with $H$. pylori infection. Like VacA, CagA modulates host cell function in several ways, primarily by disrupting signal transduction within intoxicated cells.

In principle, VacA and CagA are fundamentally different in their contributions to modulating the host epithelium. CagA, as a Type IV effector injected directly into the eukaryotic cytosol, modulates the functional properties of only those cells with which H. pylori have specifically colonized. In contrast, secreted VacA can act both proximally at the site of bacterial attachment to the epithelial membrane, as well as distally upon uninfected epithelial cells after diffusion from the site of adherent bacteria. Thus, infected epithelial cells would be predicted to be subject to the modulating effects of both VacA and CagA (Figure 3). There is some evidence that some the cellular modulatory effects of VacA and CagA might be synergistic. For example, a recent report suggests that VacA and CagA may both facilitate iron acquisition of $H$. pylori colonizing the apical surface of polarized epithelial monolayers (Tan et al., 2011), without severely damaging the host cells.
However, most studies to date however indicate that the cellular activities of VacA and CagA are primarily antagonistic. VacA and CagA inhibit each other's effects on epithelial cells (Argent et al., 2008), with CagA down-regulating cellular vacuolation (Figure 3), and VacA down-regulating the hummingbird phenotype of gastric epithelial cells associated with CagA injection. Another report demonstrated that whereas CagA activates the NFAT pathway via activation of calcineurin, VacA blocks calcineurin activation through decreased calcium influx, thereby down-regulating the NFAT pathway (Yokoyama et al., 2005).

Strikingly, the capacity of VacA to induce the death of epithelial cells is blocked by CagA (Figure 3) (Oldani et al., 2009). The authors demonstrated phosphorylated CagA blocks the ability of VacA to traffic to intracellular compartments, whereas unphosphorylated CagA blocks apoptosis in a manner that mimics Bcl2 (an anti-apoptotic factor) overexpression. CagA further inhibits VacA-dependent apoptosis by blocking the cellular uptake of VacA from the cell surface (Akada et al., 2010).

Increasing evidence suggests that VacA and CagA can functionally interact in manner that directly affects disease outcome. This idea is supported by epidemiological studies revealing significant 3-way associations between vacA alleles, cagA alleles, and the development of gastric diseases, including cancer (van Doorn et al., 1999; Yamazaki et al., 2005; Jang et al., 2010; Jones et al., 2011).

How might VacA and CagA function together to promote colonization and disease? A recent study of the molecular evolution of vacA indicates that the vacA gene and the core $H$. pylori genome do not share the same evolutionary history (Gangwer et al., 2010). The $v a c A$ and $\operatorname{cag} A$ genes are separated on the $H$. pylori genome by a considerable distance, and several lines of evidence suggest that the cag PAI was acquired more recently than vacA (Gressmann et al., 2005; Olbermann et al., 2010). This type of evolutionary history might support the idea that acquisition of the genes encoding VacA and CagA established the pro-/anti-inflammatory and pro-/anti-apoptotic balance necessary to promote long-term colonization of the human gastric mucosa.

Overall, these findings are consistent with the idea that VacA and CagA most effectively promote $H$. pylori persistence by functioning together in manner that remodels the gastric niche occupied by the bacterium, but at the same time limits the degree to which the epithelial mucosa is damaged. The capacity to limit damage to host cells and tissues during infection is an increasingly recognized strategy employed by a number of pathogenic bacteria to fine tune virulence while promoting propagation and/or persistence (Shames and Finlay, 2010).

\section{VacA AS A HOST CELL REMODELER}

VacA does not fit neatly into our current notions of intracellularacting bacterial exotoxins. Whether the p33 and p55 fragments of VacA ultimately comprise the A and B fragments corresponding to the $\mathrm{AB}$ architecture of most intracellular-acting toxins remains to be seen. The absence of a defined enzymatic activity, as well as the strong association of VacA membrane channel activity with most of the toxin's intracellular effects suggests that VacA does not rely on the power of catalytic turnover to modulate 


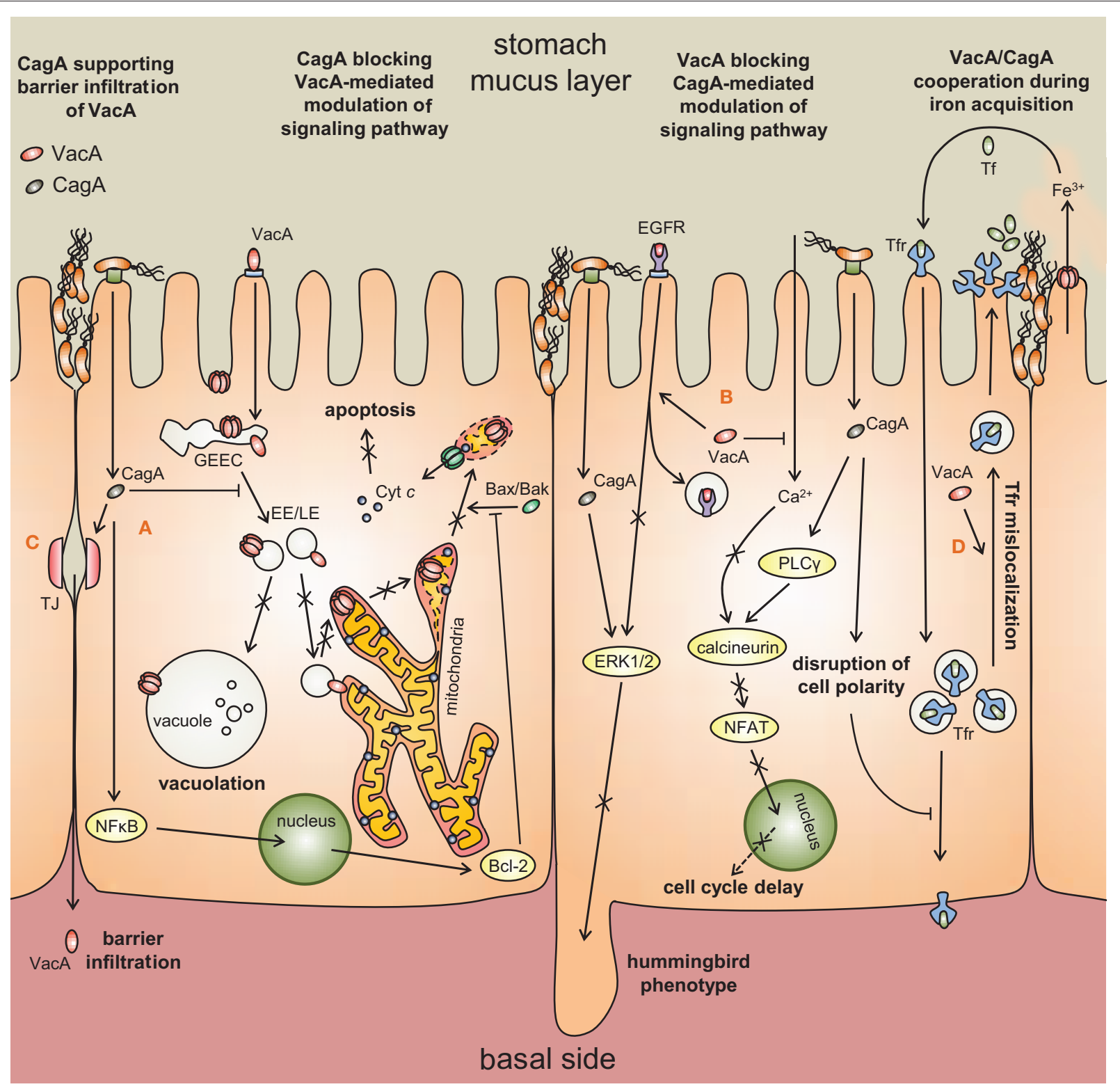

FIGURE 3 | Synergistic and antagonistic interactions between VacA and CagA. (A) CagA blocks intracellular trafficking of VacA [Oldani et al. (2009)], thereby inhibiting VacA-mediated vacuolation and apoptosis [Argent et al. (2008); Oldani et al. (2009)]. VacA-dependent apoptosis is further antagonized by CagA activation of $\mathrm{Bcl}-2$ [Oldani et al (2009)]. (B) VacA prevents CagA-mediated activation of ERK1/2 and hummingbird-like cellular morphological changes by misrouting the epidermal growth factor receptor (EGFR) [Tegtmeyer et al. (2009)]. VacA also counteracts the ability of CagA to activate NFAT, which has multiple roles in cell growth and differentiation [Yokoyama et al. (2005); Oldani et al. (2009)]. (C) CagA disruption of epithelial tight junctions (TJ) allows VacA to access underlying immune cells. (D) VacA and CagA collaborate to misdirect holotransferrin to $H$. pylori micro-colonies at the apical surface. host cells. Because toxin translocation from membrane bound compartments is generally considered a highly inefficient process, an intriguing question remains how VacA intracellular activity is mediated by channel activity at mitochondria. As suggested by recent work into the mechanism underlying the uptake and transport of VacA, perhaps VacA activity does not require toxin translocation across a membrane, but perhaps, instead, delivery by a mechanism involving membrane fusion between VacA intracellular transport vesicles and mitochondria.

\section{ACKNOWLEDGMENTS}

We acknowledge research support (NIH R01 AI045928). We offer our apologies to those investigators whose work we were unable to cite. 


\section{REFERENCES}

Abe, Y., Shodai, T., Muto, T., Mihara, K., Torii, H., Nishikawa, S., Endo, T., and Kohda, D. (2000). Structural basis of presequence recognition by the mitochondrial protein import receptor Tom20. Cell 100, 551-560.

Adrian, M., Cover, T. L., Dubochet, J., and Heuser, J. E. (2002). Multiple oligomeric states of the Helicobacter pylori vacuolating toxin demonstrated by cryoelectron microscopy. J. Mol. Biol. 318, 121-133.

Akada, J. K., Aoki, H., Torigoe, Y., Kitagawa, T., Kurazono, H., Hoshida, H., Nishikawa, J., Terai, S., Matsuzaki, M., Hirayama, T., Nakazawa, T., Akada, R., and Nakamura, K. (2010). Helicobacter pylori CagA inhibits endocytosis of cytotoxin VacA in host cells. Dis. Model Mech. 3, 605-617.

Algood, H. M., Torres, V. J., Unutmaz, D., and Cover, T. L. (2007). Resistance of primary murine CD4+ $\mathrm{T}$ cells to Helicobacter pylori vacuolating cytotoxin. Infect. Immun. 75, 334-341.

Allen, L. A., Schlesinger, L. S., and Kang, B. (2000). Virulent strains of Helicobacter pylori demonstrate delayed phagocytosis and stimulate homotypic phagosome fusion in macrophages. J. Exp. Med. 191, 115-128.

Amieva, M. R., Salama, N. R., Tompkins, L. S., and Falkow, S. (2002). Helicobacter pylori enter and survive within multivesicular vacuoles of epithelial cells. Cell. Microbiol. 4, 677-690.

Argent, R. H., Thomas, R. J., Letley, D. P., Rittig, M. G., Hardie, K. R., and Atherton, J. C. (2008). Functional association between the Helicobacter pylori virulence factors VacA and CagA. J. Med. Microbiol. 57, 145-150.

Ashorn, M., Cantet, F., Mayo, K., and Megraud, F. (2000). Cytoskeletal rearrangements induced by Helicobacter pylori strains in epithelial cell culture: possible role of the cytotoxin. Dig. Dis. Sci. 45, 1774-1780.

Ashour, A. A., Magalhaes, P. P., Mendes, E. N., Collares, G. B., De Gusmao, V. R., Queiroz, D. M., Nogueira, A. M., Rocha, G. A., and De Oliveira, C. A. (2002). Distribution of vacA genotypes in Helicobacter pylori strains isolated from Brazilian adult patients with gastritis, duodenal ulcer or gastric carcinoma. FEMS Immunol. Med. Microbiol. 33, 173-178.

Atherton, J. C., Cao, P., Peek, R. M. Jr., Tummuru, M. K., Blaser, M. J., and Cover, T. L. (1995). Mosaicism in vacuolating cytotoxin alleles of Helicobacter pylori. Association of specific vacA types with cytotoxin production and peptic ulceration. J. Biol. Chem. 270, 17771-17777.

Atherton, J. C., Peek, R. M. Jr., Tham, K. T., Cover, T. L., and Blaser, M. J. (1997). Clinical and pathological importance of heterogeneity in $v a c A$, the vacuolating cytotoxin gene of Helicobacter pylori. Gastroenterology 112, 92-99.

Atherton, J. C., Sharp, P. M., Cover, T. L., Gonzalez-Valencia, G., Peek, R. M. Jr., Thompson, S. A., Hawkey, C. J., and Blaser, M. J. (1999). Vacuolating cytotoxin (vacA) alleles of Helicobacter pylori comprise two geographically widespread types, $\mathrm{m} 1$ and $\mathrm{m} 2$, and have evolved through limited recombination. Curr. Microbiol. 39, 211-218.

Basso, D., Navaglia, F., Brigato, L., Piva, M. G., Toma, A., Greco, E., Di Mario, F., Galeotti, F., Roveroni, G., Corsini, A., and Plebani, M. (1998). Analysis of Helicobacter pylori vacA and $\operatorname{cag} A$ genotypes and serum antibody profile in benign and malignant gastroduodenal diseases. Gut 43, 182-186.

Basso, D., Zambon, C. F., Letley, D. P. Stranges, A., Marchet, A., Rhead, J. L., Schiavon, S., Guariso, G., Ceroti, M., Nitti, D., Rugge, M., Plebani, M., and Atherton, J. C. (2008). Clinical relevance of Helicobacter pylori cagA and vacA gene polymorphisms. Gastroenterology 135, 91-99.

Bjorkholm, B., Zhukhovitsky, V., Lofman, C., Hulten, K., Enroth, H., Block, M., Rigo, R., Falk, P., and Engstrand, L. (2000). Helicobacter pylori entry into human gastric epithelial cells: a potential determinant of virulence, persistence, and treatment failures. Helicobacter 5 148-154.

Blanke, S. R. (2005). Micro-managing the executioner: pathogen targeting of mitochondria. Trends Microbiol. 13, 64-71.

Boncristiano, M., Paccani, S. R., Barone, S., Ulivieri, C., Patrussi, L., Ilver, D., Amedei, A., D'Elios, M. M., Telford, J. L., and Baldari, C. T. (2003). The Helicobacter pylori vacuolating toxin inhibits $\mathrm{T}$ cell activation by two independent mechanisms. J. Exp. Med. 198, 1887-1897.

Boquet, P., Ricci, V., Galmiche, A., and Gauthier, N. C. (2003). Gastric cell apoptosis and $H$. pylori: has the main function of VacA finally been identified? Trends Microbiol. 11, 410-413.

Brest, P., Hofman, V., Lassalle, S. Cesaro, A., Ricci, V., Selva, E., Auberger, P., and Hofman, P. (2006). Human polymorphonuclear leukocytes are sensitive in vitro to Helicobacter pylori vaca toxin. Helicobacter 11, 544-555.

Burroni, D., Lupetti, P., Pagliaccia, C., Reyrat, J. M., Dallai, R. Rappuoli, R., and Telford, J. L. (1998). Deletion of the major proteolytic site of the Helicobacter pylori cytotoxin does not influence toxin activity but favors assembly of the toxin into hexameric structures. Infect. Immun. 66, 5547-5550.

Calore, F., Genisset, C., Casellato, A., Rossato, M., Codolo, G., Esposti, M D., Scorrano, L., and de Bernard, M (2010). Endosome-mitochondria juxtaposition during apoptosis induced by $H$. pylori VacA. Cell Death Differ. 17, 1707-1716.

Campello, S., Tombola, F., Cabrini, G., and Zoratti, M. (2002). The vacuolating toxin of Helicobacter pylori mimicks the CFTR-mediated chloride conductance. FEBS Lett. 532, 237-240.

Caputo, R., Tuccillo, C., Manzo, B. A., Zarrilli, R., Tortora, G., Blanco Cdel, V., Ricci, V., Ciardiello, F., and Romano, M. (2003). Helicobacter pylori VacA toxin up-regulates vascular endothelial growth factor expression in MKN 28 gastric cells through an epidermal growth factor receptor-, cyclooxygenase-2dependent mechanism. Clin. Cancer Res. 9, 2015-2021.

Carter, E. L., Flugga, N., Boer, J. L., Mulrooney, S. B., and Hausinger, R. P. (2009). Interplay of metal ions and urease. Metallomics 1, 207-221.

Cereghetti, G. M., Stangherlin, A. Martins De Brito, O., Chang, C. R., Blackstone, C., Bernardi, P., and Scorrano, L. (2008) Dephosphorylation by calcineurin regulates translocation of Drp1 to mitochondria. Proc. Natl. Acad. Sci. U.S.A. 105, 15803-15808.

Chung, C., Olivares, A., Torres, E., Yilmaz, O., Cohen, H., and PerezPerez, G. (2010). Diversity of VacA intermediate region among Helicobacter pylori strains from several regions of the world. J. Clin. Microbiol. 48, 690-696.

Compare, D., Rocco, A., and Nardone, G. (2010). Risk factors in gastric cancer. Eur. Rev. Med. Pharmacol. Sci. 14, 302-308.

Correa, P., and Houghton, J. (2007). Carcinogenesis of Helicobacter pylori. Gastroenterology 133, 659-672.

Cover, T. L., and Blanke, S. R. (2005). Helicobacter pylori VacA, a paradigm for toxin multifunctionality. Nat. Rev. Microbiol. 3, 320-332.

Cover, T. L., and Blaser, M. J. (1992). Purification and characterization of the vacuolating toxin from Helicobacter pylori. J. Biol. Chem. 267, 10570-10575.

Cover, T. L., and Blaser, M. J. (2009). Helicobacter pylori in health and disease. Gastroenterology 136, 1863-1873.

Cover, T. L., Cao, P., Lind, C. D. Tham, K. T., and Blaser, M. J. (1993). Correlation between vacuolating cytotoxin production by Helicobacter pylori isolates in vitro and in vivo. Infect. Immun. 61, 5008-5012.

Cover, T. L., Dooley, C. P., and Blaser, M. J. (1990). Characterization of and human serologic response to proteins in Helicobacter pylori broth culture supernatants with vacuolizing cytotoxin activity. Infect. Immun. 58, 603-610.

Cover, T. L., Hanson, P. I., and Heuser, J. E. (1997). Acid-induced dissociation of VacA, the Helicobacter pylori vacuolating cytotoxin, reveals its pattern of assembly. J. Cell Biol. 138, 759-769.

Cover, T. L., Krishna, U. S., Israel, D. A., and Peek, R. M. Jr. (2003). Induction of gastric epithelial cell apoptosis by Helicobacter pylori vacuolating cytotoxin. Cancer Res. 63 951-957

Cover, T. L., Puryear, W., Perez-Perez, G. I., and Blaser, M. J. (1991). Effect of urease on HeLa cell vacuolation induced by Helicobacter pylori cytotoxin. Infect. Immun. 59, 1264-1270.

Czajkowsky, D. M., Iwamoto, H., Cover, T. L., and Shao, Z. (1999). The vacuolating toxin from Helicobacter pylori forms hexameric pores in lipid bilayers at low $\mathrm{pH}$. Proc. Natl. Acad. Sci. U.S.A. 96, 2001-2006.

Czajkowsky, D. M., Iwamoto, H., Szabo, G., Cover, T. L., and Shao, Z. (2005). Mimicry of a host anion channel by a Helicobacter pylori pore-forming toxin. Biophys. J. 89, 3093-3101.

de Bernard, M., Arico, B., Papini, E., Rizzuto, R., Grandi, G., Rappuoli, R., and Montecucco, C. (1997). Helicobacter pylori toxin VacA induces vacuole formation by acting in the cell cytosol. Mol. Microbiol. 26, 665-674.

de Bernard, M., Burroni, D., Papini, E., Rappuoli, R., Telford, J. and Montecucco, C. (1998). 
Identification of the Helicobacter pylori VacA toxin domain active in the cell cytosol. Infect. Immun. 66, 6014-6016.

de Bernard, M., Cappon, A., Del Giudice, G., Rappuoli, R., and Montecucco, C. (2004). The multiple cellular activities of the VacA cytotoxin of Helicobacter pylori. Int. J. Med. Microbiol. 293, 589-597.

de Bernard, M., Cappon, A., Pancotto, L., Ruggiero, P., Rivera, J., Del Giudice, G., and Montecucco, C. (2005). The Helicobacter pylori VacA cytotoxin activates RBL-2H3 cells by inducing cytosolic calcium oscillations. Cell. Microbiol. 7, 191-198.

de Bernard, M., Moschioni, M., Habermann, A., Griffiths, G., and Montecucco, C. (2002). Cell vacuolization induced by Helicobacter pylori VacA cytotoxin does not depend on late endosomal SNAREs. Cell. Microbiol. 4, 11-18.

de Bernard, M., Moschioni, M., Napolitani, G., Rappuoli, R., and Montecucco, C. (2000). The VacA toxin of Helicobacter pylori identifies a new intermediate filament-interacting protein. $E M B O$ J. 19, 48-56.

Debellis, L., Papini, E., Caroppo, R., Montecucco, C., and Curci, S. (2001). Helicobacter pylori cytotoxin VacA increases alkaline secretion in gastric epithelial cells. Am. J. Physiol. Gastrointest. Liver Physiol. 281, G1440-G1448.

de Gusmao, V. R., Nogueira Mendes, E., De Magalhaes Queiroz, D. M., Aguiar Rocha, G., Camargos Rocha, A. M., Ramadan Ashour, A. A., and Teles Carvalho, A. S. (2000). vacA genotypes in Helicobacter pylori strains isolated from children with and without duodenal ulcer in Brazil. J. Clin. Microbiol. 38, 2853-2857.

Domanska, G., Motz, C., Meinecke, M., Harsman, A., Papatheodorou, P., Reljic, B., Dian-Lothrop, E. A., Galmiche, A., Kepp, O., Becker, L., Gunnewig, K., Wagner, R., and Rassow, J. (2010). Helicobacter pylori VacA toxin/subunit p34: targeting of an anion channel to the inner mitochondrial membrane. PLoS Pathog. 6:e1000878. doi: 10.1371/journal.ppat.1000878

El-Bez, C., Adrian, M., Dubochet, J., and Cover, T. L. (2005). High resolution structural analysis of Helicobacter pylori VacA toxin oligomers by cryo-negative staining electron microscopy. J. Struct. Biol. 151, 215-228.

Evans, D. J. Jr., Queiroz, D. M., Mendes, E. N., and Evans, D. G. (1998). Diversity in the variable region of Helicobacter pylori cagA gene involves more than simple repetition of a 102-nucleotide sequence. Biochem. Biophys. Res. Commun. $245,780-784$.

Fan, X., Crowe, S. E., Behar, S., Gunasena, H., Ye, G., Haeberle, H., Van Houten, N., Gourley, W. K., Ernst, P. B., and Reyes, V. E. (1998). The effect of class II major histocompatibility complex expression on adherence of Helicobacter pylori and induction of apoptosis in gastric epithelial cells: a mechanism for $\mathrm{T}$ helper cell type 1-mediated damage. J. Exp. Med. 187, 1659-1669.

Figueiredo, C., Machado, J. C., Pharoah, P., Seruca, R., Sousa, S., Carvalho, R., Capelinha, A. F., Quint, W., Caldas, C., van Doorn, L. J., Carneiro, F., and SobrinhoSimoes, M. (2002). Helicobacter pylori and interleukin 1 genotyping: an opportunity to identify high-risk individuals for gastric carcinoma. J. Natl. Cancer Inst. 94, 1680-1687.

Figueiredo, C., van Doorn, L. J., Nogueira, C., Soares, J. M., Pinho, C., Figueira, P., Quint, W. G., and Carneiro, F. (2001). Helicobacter pylori genotypes are associated with clinical outcome in Portuguese patients and show a high prevalence of infections with multiple strains. Scand. J. Gastroenterol. 36, 128-135.

Figura, N., Guglielmetti, P., Rossolini, A., Barberi, A., Cusi, G., Musmanno, R. A., Russi, M. and Quaranta, S. (1989). Cytotoxin production by Campylobacter pylori strains isolated from patients with peptic ulcers and from patients with chronic gastritis only. J. Clin. Microbiol. 27, 225-226.

Fischer, W., Buhrdorf, R., Gerland, E., and Haas, R. (2001). Outer membrane targeting of passenger proteins by the vacuolating cytotoxin autotransporter of Helicobacter pylori. Infect. Immun. 69, 6769-6775.

Fischer, W., Gebert, B., and Haas, R. (2004). Novel activities of the Helicobacter pylori vacuolating cytotoxin: from epithelial cells towards the immune system. Int. J. Med. Microbiol. 293, 539-547.

Fischer, W., Prassl, S., and Haas, R. (2009). Virulence mechanisms and persistence strategies of the human gastric pathogen Helicobacter pylori. Curr. Top. Microbiol. Immunol. 337, 129-171.

Foo, J. H., Culvenor, J. G., Ferrero, R. L., Kwok, T., Lithgow, T., and Gabriel, K. (2010). Both the p33 and p55 subunits of the Helicobacter pylori VacA toxin are targeted to mammalian mitochondria. J. Mol. Biol. 401, 792-798.

Forsyth, M. H., Atherton, J. C., Blaser, M. J., and Cover, T. L. (1998). Heterogeneity in levels of vacuolating cytotoxin gene ( $\mathrm{vacA})$ transcription among Helicobacter pylori strains. Infect. Immun. 66, 3088-3094.

Fujikawa, A., Shirasaka, D., Yamamoto, S., Ota, H., Yahiro, K., Fukada, M., Shintani, T., Wada, A., Aoyama, N. Hirayama, T., Fukamachi, H., and Noda, M. (2003). Mice deficient in protein tyrosine phosphatase receptor type $\mathrm{Z}$ are resistant to gastric ulcer induction by VacA of Helicobacter pylori. Nat. Genet. 33, 375-381.

Galmiche, A., and Rassow, J. (2010). Targeting of Helicobacter pylori VacA to mitochondria. Gut Microbes 1, 392-395.

Galmiche, A., Rassow, J., Doye, A., Cagnol, S., Chambard, J. C., Contamin, S., De Thillot, V., Just, I., Ricci, V., Solcia, E., Van Obberghen, E., and Boquet, P. (2000). The $\mathrm{N}$-terminal $34 \mathrm{kDa}$ fragment of Helicobacter pylori vacuolating cytotoxin targets mitochondria and induces cytochrome $\mathrm{c}$ release. ЕМBO J. 19, 6361-6370.

Gangwer, K. A., Mushrush, D. J. Stauff, D. L., Spiller, B., Mcclain, M. S., Cover, T. L., and Lacy, D. B. (2007). Crystal structure of the Helicobacter pylori vacuolating toxin p55 domain. Proc. Natl. Acad. Sci. U.S.A. 104, 16293-16298.

Gangwer, K. A., Shaffer, C. L. Suerbaum, S., Lacy, D. B., Cover, T. L., and Bordenstein, S. R. (2010). Molecular evolution of the Helicobacter pylori vacuolating toxin gene vacA. J. Bacteriol. 192, 6126-6135.

Garner, J. A., and Cover, T. L. (1996). Binding and internalization of the Helicobacter pylori vacuolating cytotoxin by epithelial cells. Infect. Immun. 64, 4197-4203.

Gauthier, N. C., Monzo, P., Gonzalez, T., Doye, A., Oldani, A., Gounon, P., Ricci, V., Cormont, M., and Boquet, P. (2007). Early endosomes associated with dynamic F-actin structures are required for late trafficking of H. pylori VacA toxin. J. Cell Biol. 177, 343-354.

Gauthier, N. C., Monzo, P., Kaddai, V., Doye, A., Ricci, V., and Boquet, P. (2005). Helicobacter pylori VacA cytotoxin: a probe for a clathrinindependent and Cdc42-dependent pinocytic pathway routed to late endosomes. Mol. Biol. Cell 16 4852-4866.
Gauthier, N. C., Ricci, V., Gounon, P., Doye, A., Tauc, M., Poujeol, P., and Boquet, P. (2004). Glycosylphosphatidylinositol-anchored proteins and actin cytoskeleton modulate chloride transport by channels formed by the Helicobacter pylori vacuolating cytotoxin VacA in HeLa cells. J. Biol. Chem. 279, 9481-9489.

Gebert, B., Fischer, W., Weiss, E., Hoffmann, R., and Haas, R. (2003). Helicobacter pylori vacuolating cytotoxin inhibits $\mathrm{T}$ lymphocyte activation. Science 301, 1099-1102.

Geisse, N. A., Cover, T. L., Henderson, R. M., and Edwardson, J. M. (2004). Targeting of Helicobacter pylori vacuolating toxin to lipid raft membrane domains analysed by atomic force microscopy. Biochem. J. 381, 911-917.

Genisset, C., Puhar, A., Calore, F., de Bernard, M., Dell'Antone, P., and Montecucco, C. (2007). The concerted action of the Helicobacter pylori cytotoxin VacA and of the $\mathrm{v}$-ATPase proton pump induces swelling of isolated endosomes. Cell. Microbiol. 9, 1481-1490.

Gerhard, M., Lehn, N., Neumayer, N., Boren, T., Rad, R., Schepp, W., Miehlke, S., Classen, M., and Prinz, C. (1999). Clinical relevance of the Helicobacter pylori gene for blood-group antigen-binding adhesin. Proc. Natl. Acad. Sci. U.S.A. 96, 12778-12783.

Ghiara, P., Marchetti, M., Blaser, M. J., Tummuru, M. K., Cover, T. L. Segal, E. D., Tompkins, L. S., and Rappuoli, R. (1995). Role of the Helicobacter pylori virulence factors vacuolating cytotoxin, CagA, and urease in a mouse model of disease. Infect. Immun. 63, 4154-4160.

Gonzalez-Rivera, C., Gangwer, K. A., Mcclain, M. S., Eli, I. M., Chambers, M. G., Ohi, M. D., Lacy, D. B., and Cover, T. L. (2010). Reconstitution of Helicobacter pylori VacA toxin from purified components. Biochemistry 49, 5743-5752.

Gressmann, H., Linz, B., Ghai, R., Pleissner, K. P., Schlapbach, R., Yamaoka, Y., Kraft, C., Suerbaum, S., Meyer, T. F., and Achtman, M. (2005). Gain and loss of multiple genes during the evolution of Helicobacter pylori. PLoS Genet. 1:e43. doi: 10.1371/journal.pgen.0010043

Guarino, A., Bisceglia, M., Canani, R. B., Boccia, M. C., Mallardo, G., Bruzzese, E., Massari, P., Rappuoli, R., and Telford, J. (1998). Enterotoxic effect of the vacuolating 
toxin produced by Helicobacter pylori in Caco-2 cells. J. Infect. Dis. 178, 1373-1378.

Gupta, V. R., Patel, H. K., Kostolansky, S. S., Ballivian, R. A., Eichberg, J., and Blanke, S. R. (2008), Sphingomyelin functions as a novel receptor for Helicobacter pylori VacA. PLoS Pathog. 4:e1000073. doi: 10.1371/journal.ppat.1000073

Gupta, V. R., Wilson, B. A., and Blanke, S. R. (2010). Sphingomyelin is important for the cellular entry and intracellular localization of Helicobacter pylori VacA. Cell. Microbiol. 12, 1517-1533.

Han, S. R., Schreiber, H. J., Bhakdi, S., Loos, M., and Maeurer, M. J. (1998). vacA genotypes and genetic diversity in clinical isolates of Helicobacter pylori. Clin. Diagn. Lab. Immunol. 5, 139-145.

Hennig, E. E., Godlewski, M. M., Butruk, E., and Ostrowski, J. (2005). Helicobacter pylori VacA cytotoxin interacts with fibronectin and alters HeLa cell adhesion and cytoskeletal organization in vitro. FEMS Immunol. Med. Microbiol. 44, 143-150.

Hisatsune, J., Nakayama, M., Isomoto, H., Kurazono, H., Mukaida, N. Mukhopadhyay, A. K., Azuma, T., Yamaoka, Y., Sap, J., Yamasaki, E., Yahiro, K., Moss, J., and Hirayama, T. (2008). Molecular characterization of Helicobacter pylori VacA induction of IL-8 in U937 cells reveals a prominent role for p38MAPK in activating transcription factor-2, cAMP response element binding protein, and NFkappaB activation. J. Immunol. 180, 5017-5027.

Hisatsune, J., Yamasaki, E., Nakayama, M., Shirasaka, D., Kurazono, H., Katagata, Y., Inoue, H., Han, J., Sap, J., Yahiro, K., Moss, J., and Hirayama, T. (2007). Helicobacter pylori VacA enhances prostaglandin E2 production through induction of cyclooxygenase 2 expression via a p38 mitogen-activated protein kinase/activating transcription factor 2 cascade in AZ-521 cells. Infect. Immun. 75, 4472-4481.

Hofman, V. J., Moreilhon, C., Brest, P. D., Lassalle, S., Le Brigand, K., Sicard, D., Raymond, J., Lamarque, D., Hebuterne, X. A., Mari, B., Barbry, P. J., and Hofman, P. M. (2007). Gene expression profiling in human gastric mucosa infected with Helicobacter pylori. Mod. Pathol. 20, 974-989.

Ito, Y., Azuma, T., Ito, S., Suto, H., Miyaji, H., Yamazaki, Y., Kohli, Y., and Kuriyama, M. (1998). Fulllength sequence analysis of the $v a c A$ gene from cytotoxic and noncytotoxic Helicobacter pylori. J. Infect. Dis. 178, 1391-1398.

Iwamoto, H., Czajkowsky, D. M., Cover, T. L., Szabo, G., and Shao, Z. (1999). VacA from Helicobacter pylori: a hexameric chloride channel. FEBS Lett. 450, 101-104.

Jain, P., Luo, Z. Q., and Blanke, S. R. (2011). Helicobacter pylori vacuolating cytotoxin $\mathrm{A}$ (VacA) engages the mitochondrial fission machinery to induce host cell death. Proc. Natl. Acad. Sci. U.S.A. 108, 16032-16037.

Jang, S., Jones, K. R., Olsen, C. H., Joo, Y. M., Yoo, Y. J., Chung, I. S., Cha, J. H., and Merrell, D. S. (2010). Epidemiological link between gastric disease and polymorphisms in VacA and CagA. J. Clin. Microbiol. $48,559-567$.

Ji, X., Fernandez, T., Burroni, D., Pagliaccia, C., Atherton, J. C., Reyrat, J. M., Rappuoli, R., and Telford, J. L. (2000). Cell specificity of Helicobacter pylori cytotoxin is determined by a short region in the polymorphic midregion. Infect. Immun. 68, 3754-3757.

Ji, X., Frati, F., Barone, S., Pagliaccia, C., Burroni, D., Xu, G., Rappuoli, R., Reyrat, J. M., and Telford, J. L. (2002). Evolution of functional polymorphism in the gene coding for the Helicobacter pylori cytotoxin. FEMS Microbiol. Lett. 206, 253-258.

Jones, K. R., Jang, S., Chang, J. Y., Kim, J., Chung, I. S., Olsen, C. H., Merrell, D. S., and Cha, J. H. (2011). Polymorphisms in the intermediate region of VacA impact Helicobacter pylori-induced disease development. J. Clin. Microbiol. 49, 101-110.

Jones, N. L., Day, A. S., Jennings, H., Shannon, P. T., Galindo-Mata, E., and Sherman, P. M. (2002). Enhanced disease severity in Helicobacter pylori-infected mice deficient in Fas signaling. Infect. Immun. 70, 2591-2597.

Jones, N. L., Shannon, P. T., Cutz, E., Yeger, H., and Sherman, P. M. (1997). Increase in proliferation and apoptosis of gastric epithelial cells early in the natural history of Helicobacter pylori infection. Am. J. Pathol. 151, 1695-1703.

Kawahara, T., Teshima, S., Kuwano, Y., Oka, A., Kishi, K., and Rokutan, K. (2001). Helicobacter pylori lipopolysaccharide induces apoptosis of cultured guinea pig gastric mucosal cells. Am. J. Physiol. Gastrointest. Liver Physiol. 281, G726-G734.

Kidd, M., Lastovica, A. J., Atherton, J. C., and Louw, J. A. (1999). Heterogeneity in the Helicobacter pylori vacA and cagA genes: association with gastroduodenal disease in South Africa? Gut 45, 499-502.

Kim, J. M., Kim, J. S., Lee, J. Y., Kim, Y. J., Youn, H. J., Kim, I. Y., Chee, Y. J., Oh, Y. K., Kim, N., Jung, H. C., and Song, I. S (2007). Vacuolating cytotoxin in Helicobacter pylori water-soluble proteins upregulates chemokine expression in human eosinophils via $\mathrm{Ca} 2+$ influx, mitochondria reactive oxygen intermediates, and NF-kappaB activation. Infect. Immun. 75, 3373-3381.

Kimura, M., Goto, S., Wada, A., Yahiro, K., Niidome, T., Hatakeyama, T., Aoyagi, H., Hirayama, T., and Kondo, T. (1999). Vacuolating cytotoxin purified from Helicobacter pylori causes mitochondrial damage in human gastric cells. Microb. Pathog. 26, 45-52.

Kuck, D., Kolmerer, B., Iking-Konert, C., Krammer, P. H., Stremmel, W., and Rudi, J. (2001). Vacuolating cytotoxin of Helicobacter pylori induces apoptosis in the human gastric epithelial cell line AGS Infect. Immun. 69, 5080-5087.

Lanzavecchia, S., Bellon, P. L., Lupetti, P., Dallai, R., Rappuoli, R., and Telford, J. L. (1998). Threedimensional reconstruction of metal replicas of the Helicobacter pylori vacuolating cytotoxin. $J$. Struct. Biol. 121, 9-18.

Letley, D. P., and Atherton, J. C. (2000). Natural diversity in the $\mathrm{N}$ terminus of the mature vacuolating cytotoxin of Helicobacter pylori determines cytotoxin activity. J. Bacteriol. 182, 3278-3280.

Letley, D. P., Rhead, J. L., Twells, R. J., Dove, B., and Atherton, J. C. (2003). Determinants of non-toxicity in the gastric pathogen Helicobacter pylori. J. Biol. Chem. 278, 26734-26741.

Leunk, R. D., Johnson, P. T., David, B. C., Kraft, W. G., and Morgan, D. R. (1988). Cytotoxic activity in brothculture filtrates of Campylobacter pylori. J. Med. Microbiol. 26, 93-99.

Li, Y., Wandinger-Ness, A., Goldenring, J. R., and Cover, T. L. (2004). Clustering and redistribution of late endocytic compartments in response to Helicobacter pylori vacuolating toxin. Mol. Biol. Cell 15, 1946-1959.

Lupetti, P., Heuser, J. E., Manetti, R., Massari, P., Lanzavecchia, S., Bellon, P. L., Dallai, R., Rappuoli, R., and Telford, J. L. (1996). Oligomeric and subunit structure of the Helicobacter pylori vacuolating cytotoxin. J. Cell Biol. 133, 801-807.
Mannick, E. E., Bravo, L. E., Zarama, G., Realpe, J. L., Zhang, X. J., Ruiz, B., Fontham, E. T., Mera, R., Miller, M. J., and Correa, P. (1996). Inducible nitric oxide synthase, nitrotyrosine, and apoptosis in Helicobacter pylori gastritis: effect of antibiotics and antioxidants. Cancer Res. 56, 3238-3243.

Marchetti, M., Arico, B., Burroni, D., Figura, N., Rappuoli, R., and Ghiara, P. (1995). Development of a mouse model of Helicobacter pylori infection that mimics human disease. Science 267, 1655-1658.

Matsumoto, A., Isomoto, H., Nakayama, M., Hisatsune, J., Nishi, Y., Nakashima, Y., Matsushima, K., Kurazono, H., Nakao, K., Hirayama, T., and Kohno, S. (2011). Helicobacter pylori VacA reduces the cellular expression of STAT3 and pro-survival $\mathrm{Bcl}-2$ family proteins, $\mathrm{Bcl}-2$ and $\mathrm{Bcl}-\mathrm{XL}$, leading to apoptosis in gastric epithelial cells. Dig. Dis. Sci. 56, 999-1006.

McClain, M. S., Cao, P., Iwamoto, H., Vinion-Dubiel, A. D., Szabo, G., Shao, Z., and Cover, T. L. (2001). A 12-amino-acid segment, present in type s2 but not type s1 Helicobacter pylori VacA proteins, abolishes cytotoxin activity and alters membrane channel formation. J. Bacteriol. 183, 6499-6508.

McClain, M. S., Iwamoto, H., Cao, P., Vinion-Dubiel, A. D., Li, Y., Szabo, G., Shao, Z., and Cover, T. L. (2003). Essential role of a GXXXG motif for membrane channel formation by Helicobacter pylori vacuolating toxin. J. Biol. Chem. 278, 12101-12108.

McClain, M. S., Schraw, W., Ricci, V., Boquet, P., and Cover, T. L. (2000). Acid activation of Helicobacter pylori vacuolating cytotoxin (VacA) results in toxin internalization by eukaryotic cells. Mol. Microbiol. 37, 433-442.

Menaker, R. J., Ceponis, P. J., and Jones, N. L. (2004). Helicobacter pylori induces apoptosis of macrophages in association with alterations in the mitochondrial pathway. Infect. Immun. 72, 2889-2898.

Miehlke, S., Kirsch, C., AghaAmiri, K., Gunther, T., Lehn, N., Malfertheiner, P., Stolte, M., Ehninger, G., and Bayerdorffer, E. (2000). The Helicobacter pylori vacA s1, $\mathrm{ml}$ genotype and cagA is associated with gastric carcinoma in Germany. Int. J. Cancer 87, 322-327.

Mobley, H. L., Island, M. D., and Hausinger, R. P. (1995). Molecular biology of microbial ureases. Microbiol. Rev. 59, 451-480. 
Molinari, M., Galli, C., Norais, N., Telford, J. L., Rappuoli, R., Luzio, J. P., and Montecucco, C. (1997). Vacuoles induced by Helicobacter pylori toxin contain both late endosomal and lysosomal markers. J. Biol. Chem. 272, 25339-25344.

Molinari, M., Salio, M., Galli, C., Norais, N., Rappuoli, R., Lanzavecchia, A., and Montecucco, C. (1998). Selective inhibition of Ii-dependent antigen presentation by Helicobacter pylori toxin VacA. J. Exp. Med. 187, 135-140.

Montecucco, C., and de Bernard, M. (2003). Molecular and cellular mechanisms of action of the vacuolating cytotoxin (VacA) and neutrophil-activating protein (HP-NAP) virulence factors of Helicobacter pylori. Microbes Infect. 5, 715-721.

Montecucco, C., and Rappuoli, R. (2001). Living dangerously: how Helicobacter pylori survives in the human stomach. Nat. Rev. Mol. Cell Biol. 2, 457-466.

Morbiato, L., Tombola, F., Campello, S., Del Giudice, G., Rappuoli, R., Zoratti, M., and Papini, E. (2001). Vacuolation induced by VacA toxin of Helicobacter pylori requires the intracellular accumulation of membrane permeant bases, $\mathrm{Cl}(-)$ and water. FEBS Lett. 508, 479-483.

Moss, S. F., Calam, J., Agarwal, B., Wang, S., and Holt, P. R. (1996). Induction of gastric epithelial apoptosis by Helicobacter pylori. Gut 38, 498-501.

Nakayama, M., Hisatsune, J., Yamasaki, E., Isomoto, H., Kurazono, H., Hatakeyama, M., Azuma, T., Yamaoka, Y., Yahiro, K., Moss, J., and Hirayama, T. (2009). Helicobacter pylori VacA-induced inhibition of GSK3 through the PI3K/Akt signaling pathway. J. Biol. Chem. 284, 1612-1619.

Nakayama, M., Kimura, M., Wada, A., Yahiro, K., Ogushi, K., Niidome, T., Fujikawa, A., Shirasaka, D., Aoyama, N., Kurazono, H., Noda, M., Moss, J., and Hirayama, T. (2004). Helicobacter pylori VacA activates the p38/activating transcription factor 2-mediated signal pathway in AZ-521 cells. J. Biol. Chem. 279, 7024-7028.

Nguyen, V. Q., Caprioli, R. M., and Cover, T. L. (2001). Carboxyterminal proteolytic processing of Helicobacter pylori vacuolating toxin. Infect. Immun. 69, 543-546.

Nogueira, C., Figueiredo, C., Carneiro, F., Gomes, A. T., Barreira, R., Figueira, P., Salgado, C., Belo, L., Peixoto, A., Bravo, J. C., Bravo,
L. E., Realpe, J. L., Plaisier, A. P., Quint, W. G., Ruiz, B., Correa, P., and van Doorn, L. J. (2001). Helicobacter pylori genotypes may determine gastric histopathology. Am. J. Pathol. 158, 647-654.

Ogura, K., Maeda, S., Nakao, M., Watanabe, T., Tada, M., Kyutoku, T., Yoshida, H., Shiratori, Y., and Omata, M. (2000). Virulence factors of Helicobacter pylori responsible for gastric diseases in Mongolian gerbil. J. Exp. Med. 192, 1601-1610.

Olbermann, P., Josenhans, C., Moodley, Y., Uhr, M., Stamer, C., Vauterin, M., Suerbaum, S., Achtman, M., and Linz, B. (2010). A global overview of the genetic and functional diversity in the Helicobacter pylori cag pathogenicity island. PLoS Genet. 6:e1001069. doi: 10.1371/journal.pgen.1001069

Oldani, A., Cormont, M., Hofman, V., Chiozzi, V., Oregioni, O., Canonici, A., Sciullo, A., Sommi, P., Fabbri, A., Ricci, V., and Boquet, P. (2009). Helicobacter pylori counteracts the apoptotic action of its VacA toxin by injecting the CagA protein into gastric epithelial cells. PLoS Pathog. 5:e1000603. doi: 10.1371/journal.ppat.1000603

Oswald-Richter, K., Torres, V. J., Sundrud, M. S., Vancompernolle, S. E., Cover, T. L., and Unutmaz, D. (2006). Helicobacter pylori VacA toxin inhibits human immunodeficiency virus infection of primary human T cells. J. Virol. 80, 11767-11775.

Pagliaccia, C., de Bernard, M., Lupetti, P., Ji, X., Burroni, D., Cover, T. L., Papini, E., Rappuoli, R., Telford, J. L., and Reyrat, J. M. (1998). The $\mathrm{m} 2$ form of the Helicobacter pylori cytotoxin has cell type-specific vacuolating activity. Proc. Natl. Acad. Sci. U.S.A. 95, 10212-10217.

Pai, R., Sasaki, E., and Tarnawski, A. S. (2000). Helicobacter pylori vacuolating cytotoxin (VacA) alters cytoskeleton-associated proteins and interferes with reepithelialization of wounded gastric epithelial monolayers. Cell Biol. Int. 24, 291-301.

Papini, E., de Bernard, M., Milia, E., Bugnoli, M., Zerial, M., Rappuoli, R., and Montecucco, C. (1994). Cellular vacuoles induced by Helicobacter pylori originate from late endosomal compartments. Proc. Natl. Acad. Sci. U.S.A. 91, 9720-9724.

Papini, E., Gottardi, E., Satin, B., de Bernard, M., Massari, P., Telford, J., Rappuoli, R., Sato, S. B., and Montecucco, C. (1996). The vacuolar ATPase proton pump is present on intracellular vacuoles induced by Helicobacter pylori. J. Med. Microbiol. 45, 84-89.

Papini, E., Satin, B., Bucci, C., de Bernard, M., Telford, J. L., Manetti, R., Rappuoli, R., Zerial, M., and Montecucco, C. (1997). The small GTP binding protein rab7 is essential for cellular vacuolation induced by Helicobacter pylori cytotoxin. EMBO J. 16, 15-24.

Peek, R. M. Jr., Vaezi, M. F., Falk, G. W., Goldblum, J. R., Perez-Perez, G. I., Richter, J. E., and Blaser M. J. (1999). Role of Helicobacter pylori $\operatorname{cag} A(+)$ strains and specific host immune responses on the development of premalignant and malignant lesions in the gastric cardia. Int. J. Cancer 82, 520-524.

Peek, R. M. Jr., Wirth, H. P., Moss, S. F., Yang, M., Abdalla, A. M. Tham, K. T., Zhang, T., Tang, L. H., Modlin, I. M., and Blaser, M J. (2000). Helicobacter pylori alters gastric epithelial cell cycle events and gastrin secretion in Mongolian gerbils. Gastroenterology 118, 48-59.

Petersen, A. M., Sorensen, K., Blom, J., and Krogfelt, K. A. (2001). Reduced intracellular survival of Helicobacter pylori vacA mutants in comparison with their wild-types indicates the role of VacA in pathogenesis. FEMS Immunol. Med. Microbiol. 30, 103-108.

Polk, D. B., and Peek, R. M. Jr. (2010). Helicobacter pylori: gastric cancer and beyond. Nat. Rev. Cancer 10, 403-414.

Radin, J. N., Gonzalez-Rivera, C., Ivie, S. E., Mcclain, M. S., and Cover, T. L. (2011). Helicobacter pylori VacA induces programmed necrosis in gastric epithelial cells. Infect. Immun. 79, 2535-2543.

Raju, D., Hussey, S., Ang, M. Terebiznik, M. R., Sibony, M., Galindo-Mata, E., Gupta, V., Blanke, S. R., Delgado, A., Romero-Gallo, J., Ramjeet, M., Mascarenhas, H. Peek, R. M., Correa, P., Streutker, C., Hold, G., Kunstmann, E., Yoshimori, T., Silverberg, M. S., Girardin, S. E., Philpott, D. J., El Omar, E., and Jones, N. L. (2012). Vacuolating cytotoxin and variants in Atg1611 that disrupt autophagy promote Helicobacter pylori infection in humans. Gastroenterology. doi: 10.1053/j.gastro.2012.01.043. [Epub ahead of print].

Rassow, J. (2011). Helicobacter pylori vacuolating toxin A and apoptosis. Cell Commun. Signal. 9, 26.

Reyrat, J. M., Lanzavecchia, S., Lupetti, P., de Bernard, M., Pagliaccia, C., Pelicic, V., Charrel, M., Ulivieri,
C., Norais, N., Ji, X., Cabiaux, V., Papini, E., Rappuoli, R., and Telford, J. L. (1999). 3D imaging of the $58 \mathrm{kDa}$ cell binding subunit of the Helicobacter pylori cytotoxin. J. Mol. Biol. 290, 459-470.

Rhead, J. L., Letley, D. P., Mohammadi, M., Hussein, N., Mohagheghi, M. A., Eshagh Hosseini, M., and Atherton, J. C. (2007). A new Helicobacter pylori vacuolating cytotoxin determinant, the intermediate region, is associated with gastric cancer. Gastroenterology 133, 926-936.

Rittig, M. G., Shaw, B., Letley, D. P., Thomas, R. J., Argent, R. H., and Atherton, J. C. (2003). Helicobacter pylori-induced homotypic phagosome fusion in human monocytes is independent of the bacterial vacA and cag status. Cell. Microbiol. 5, 887-899.

Rudi, J., Kolb, C., Maiwald, M., Kuck, D., Sieg, A., Galle, P. R., and Stremmel, W. (1998). Diversity of Helicobacter pylori vacA and cagA genes and relationship to VacA and CagA protein expression, cytotoxin production, and associated diseases. J. Clin. Microbiol. 36, 944-948.

Salama, N. R., Otto, G., Tompkins, L., and Falkow, S. (2001). Vacuolating cytotoxin of Helicobacter pylori plays a role during colonization in a mouse model of infection. Infect. Immun. 69, 730-736.

Satin, B., Norais, N., Telford, J., Rappuoli, R., Murgia, M., Montecucco, C., and Papini, E. (1997). Effect of Helicobacter pylori vacuolating toxin on maturation and extracellular release of procathepsin D and on epidermal growth factor degradation. J. Biol. Chem. 272, 25022-25028.

Sewald, X., Gebert-Vogl, B., Prassl, S., Barwig, I., Weiss, E., Fabbri, M., Osicka, R., Schiemann, M. Busch, D. H., Semmrich, M., Holzmann, B., Sebo, P., and Haas, R. (2008). Integrin subunit CD18 Is the T-lymphocyte receptor for the Helicobacter pylori vacuolating cytotoxin. Cell Host Microbe 3, 20-29.

Shames, S. R., and Finlay, B. B. (2010). Breaking the stereotype: virulence factor-mediated protection of host cells in bacterial pathogenesis. PLoS Pathog. 6:e1001057. doi: 10.1371/journal.ppat.1001057

Skibinski, D. A., Genisset, C., Barone, S., and Telford, J. L. (2006). The cell-specific phenotype of the polymorphic vacA midregion is independent of the appearance of the cell surface receptor protein tyrosine 
phosphatase beta. Infect. Immun. 74, 49-55.

Smoot, D. T., Resau, J. H., Earlington, M. H., Simpson, M., and Cover, T. L. (1996). Effects of Helicobacter pylori vacuolating cytotoxin on primary cultures of human gastric epithelial cells. Gut 39, 795-799.

Strobel, S., Bereswill, S., Balig, P., Allgaier, P., Sonntag, H. G., and Kist, M. (1998). Identification and analysis of a new vacA genotype variant of Helicobacter pylori in different patient groups in Germany. J. Clin. Microbiol. 36, 1285-1289.

Sundrud, M. S., Torres, V. J., Unutmaz, D., and Cover, T. L. (2004). Inhibition of primary human $\mathrm{T}$ cell proliferation by Helicobacter pylori vacuolating toxin (VacA) is independent of VacA effects on IL-2 secretion. Proc. Natl. Acad. Sci. U.S.A. 101, 7727-7732.

Supajatura, V., Ushio, H., Wada, A., Yahiro, K., Okumura, K., Ogawa, H., Hirayama, T., and Ra, C. (2002). Cutting edge: VacA, a vacuolating cytotoxin of Helicobacter pylori, directly activates mast cells for migration and production of proinflammatory cytokines. J. Immunol. 168, 2603-2607.

Szabo, I., Brutsche, S., Tombola, F., Moschioni, M., Satin, B., Telford, J. L., Rappuoli, R., Montecucco, C., Papini, E., and Zoratti, M. (1999). Formation of anion-selective channels in the cell plasma membrane by the toxin VacA of Helicobacter pylori is required for its biological activity. EMBO J. 18, 5517-5527.

Tabel, G., Hoa, N. T., Tarnawski, A., Chen, J., Domek, M., and $\mathrm{Ma}$, T. Y. (2003). Helicobacter pylori infection inhibits healing of the wounded duodenal epithelium in vitro. J. Lab. Clin. Med. 142, 421-430.

Tan, S., Noto, J. M., Romero-Gallo, J., Peek, R. M. Jr., and Amieva, M. R. (2011). Helicobacter pylori perturbs iron trafficking in the epithelium to grow on the cell surface. PLoS Pathog. 7:e1002050. doi: 10.1371/journal.ppat.1002050

Tegtmeyer, N., Zabler, D., Schmidt, D., Hartig, R., Brandt, S., and Backert, S. (2009). Importance of EGF receptor, HER2/Neu and Erk1/2 kinase signalling for host cell elongation and scattering induced by the Helicobacter pylori CagA protein: antagonistic effects of the vacuolating cytotoxin VacA. Cell Microbiol. 11, 488-505.

Telford, J. L., Ghiara, P., Dell'Orco, M., Comanducci, M., Burroni, D., Bugnoli, M., Tecce, M. F., Censini, S., Covacci, A., Xiang, Z., Papini,
E., Montecucco, C., Parente, L., and Rappuoli, R. (1994). Gene structure of the Helicobacter pylori cytotoxin and evidence of its key role in gastric disease. J. Exp. Med. 179, 1653-1658.

Terebiznik, M. R., Raju, D., Vazquez, C. L., Torbricki, K., Kulkarni, R., Blanke, S. R., Yoshimori, T., Colombo, M. I., and Jones, N. L. (2009). Effect of Helicobacter pylori's vacuolating cytotoxin on the autophagy pathway in gastric epithelial cells. Autophagy 5, 370-379.

Terebiznik, M. R., Vazquez, C. L., Torbicki, K., Banks, D., Wang, T., Hong, W., Blanke, S. R., Colombo, M. I., and Jones, N. L. (2006). Helicobacter pylori VacA toxin promotes bacterial intracellular survival in gastric epithelial cells. Infect. Immun. 74, 6599-6614.

Tombola, F., Carlesso, C., Szabo, I., de Bernard, M., Reyrat, J. M., Telford, J. L., Rappuoli, R., Montecucco, C., Papini, E., and Zoratti, M. (1999a). Helicobacter pylori vacuolating toxin forms anion-selective channels in planar lipid bilayers: possible implications for the mechanism of cellular vacuolation. Biophys. J. 76, 1401-1409.

Tombola, F., Morbiato, L., Del Giudice, G., Rappuoli, R., Zoratti, M., and Papini, E. (2001a). The Helicobacter pylori VacA toxin is a urea permease that promotes urea diffusion across epithelia. J. Clin. Invest. 108, 929-937.

Tombola, F., Oregna, F., Brutsche, S., Szabo, I., Del Giudice, G., Rappuoli, R., Montecucco, C., Papini, E., and Zoratti, M. (1999b). Inhibition of the vacuolating and anion channel activities of the VacA toxin of Helicobacter pylori. FEBS Lett. 460, 221-225.

Tombola, F., Pagliaccia, C., Campello, S., Telford, J. L., Montecucco, C., Papini, E., and Zoratti, M. (2001b). How the loop and middle regions influence the properties of Helicobacter pylori VacA channels. Biophys. J. 81, 3204-3215.

Torres, V. J., Ivie, S. E., Mcclain, M. S., and Cover, T. L. (2005). Functional properties of the p33 and p55 domains of the Helicobacter pylori vacuolating cytotoxin. J. Biol. Chem. 280, 21107-21114.

Torres, V. J., McClain, M. S., and Cover, T. L. (2004). Interactions between $\mathrm{p}-33$ and $\mathrm{p}-55$ domains of the Helicobacter pylori vacuolating cytotoxin (VacA). J. Biol. Chem. 279, 2324-2331.

Torres, V. J., Vancompernolle, S. E., Sundrud, M. S., Unutmaz, D., and
Cover, T. L. (2007). Helicobacter pylori vacuolating cytotoxin inhibits activation-induced proliferation of human $\mathrm{T}$ and $\mathrm{B}$ lymphocyte subsets. J. Immunol. 179, 5433-5440.

Tuo, B., Song, P., Wen, G., Sewald, X., Gebert-Vogl, B., Haas, R., Manns, M., and Seidler, U. (2009) Helicobacter pylori vacuolating cytotoxin inhibits duodenal bicarbonate secretion by a histamine-dependent mechanism in mice. J. Infect. Dis. 199, 505-512.

van Doorn, L. J., Figueiredo, C., Megraud, F., Pena, S., Midolo, P., Queiroz, D. M., Carneiro, F., Vanderborght, B., Pegado, M. D., Sanna, R., De Boer, W., Schneeberger, P. M., Correa, P., Ng, E. K., Atherton, J., Blaser, M. J., and Quint, W. G. (1999). Geographic distribution of $v a c A$ allelic types of Helicobacter pylori. Gastroenterology 116, 823-830.

van Doorn, L. J., Figueiredo, C., Sanna, R., Pena, S., Midolo, P., Ng, E. K., Atherton, J. C., Blaser, M. J., and Quint, W. G. (1998). Expanding allelic diversity of Helicobacter pylori vacA. J. Clin. Microbiol. 36, 2597-2603.

Vinion-Dubiel, A. D., Mcclain, M. S., Czajkowsky, D. M., Iwamoto, H., Ye, D., Cao, P., Schraw, W., Szabo, G., Blanke, S. R., Shao, Z., and Cover, T. L. (1999). A dominant negative mutant of Helicobacter pylori vacuolating toxin (VacA) inhibits VacAinduced cell vacuolation. J. Biol. Chem. 274, 37736-37742.

Wagner, S., Beil, W., Westermann, J., Logan, R. P., Bock, C. T., Trautwein, C., Bleck, J. S., and Manns, M. P. (1997). Regulation of gastric epithelial cell growth by Helicobacter pylori: offdence for a major role of apoptosis. Gastroenterology 113, 1836-1847.

Wang, F., Xia, P., Wu, F., Wang, D., Wang, W., Ward, T., Liu, Y. Aikhionbare, F., Guo, Z., Powell, M., Liu, B., Bi, F., Shaw, A., Zhu, Z. Elmoselhi, A., Fan, D., Cover, T. L., Ding, X., and Yao, X. (2008). Helicobacter pylori VacA disrupts apical membrane-cytoskeletal interactions in gastric parietal cells. J. Biol. Chem. 283, 26714-26725.

Wang, H. J., and Wang, W. C. (2000). Expression and binding analysis of GST-VacA fusions reveals that the C-terminal approximately 100residue segment of exotoxin is crucial for binding in HeLa cells. Biochem. Biophys. Res. Commun. 278, 449-454.

Wang, H. T., Li, Z. H., Yuan, J. P., Zhao, W., Shi, X. D., Tong, S. Q., and Guo, X. K. (2005)
Effect of Helicobacter pylori VacA on gene expression of gastric cancer cells. World J. Gastroenterol. 11, 109-113.

Wang, W. C., Wang, H. J., and Kuo, C. H. (2001). Two distinctive cell binding patterns by vacuolating toxin fused with glutathione S-transferase: one high-affinity m1-specific binding and the other lower-affinity binding for variant $\mathrm{m}$ forms. Biochemistry 40, 11887-11896.

Willhite, D. C., and Blanke, S. R. (2004). Helicobacter pylori vacuolating cytotoxin enters cells, localizes to the mitochondria, and induces mitochondrial membrane permeability changes correlated to toxin channel activity. Cell Microbiol. 6, 143-154.

Willhite, D. C., Cover, T. L., and Blanke, S. R. (2003). Cellular vacuolation and mitochondrial cytochrome c release are independent outcomes of Helicobacter pylori vacuolating cytotoxin activity that are each dependent on membrane channel formation. J. Biol. Chem. 278, 48204-48209.

Willhite, D. C., Ye, D., and Blanke, S. R. (2002). Fluorescence resonance energy transfer microscopy of the Helicobacter pylori vacuolating cytotoxin within mammalian cells. Infect. Immun. 70, 3824-3832.

Yahiro, K., Niidome, T., Hatakeyama, T., Aoyagi, H., Kurazono, H. Padilla, P. I., Wada, A., and Hirayama, T. (1997). Helicobacter pylori vacuolating cytotoxin binds to the $140-\mathrm{kDa}$ protein in human gastric cancer cell lines, AZ-521 and AGS. Biochem. Biophys. Res. Commun. 238, 629-632.

Yamasaki, E., Wada, A., Kumatori, A., Nakagawa, I., Funao, J., Nakayama, M., Hisatsune, J., Kimura, M., Moss, J., and Hirayama, T. (2006). Helicobacter pylori vacuolating cytotoxin induces activation of the proapoptotic proteins Bax and Bak, leading to cytochrome $\mathrm{c}$ release and cell death, independent of vacuolation. J. Biol. Chem. 281, 11250-11259.

Yamazaki, S., Yamakawa, A., Okuda, T., Ohtani, M., Suto, H., Ito, Y., Yamazaki, Y., Keida, Y., Higashi, H. Hatakeyama, M., and Azuma, T. (2005). Distinct diversity of vacA, cagA, and cagE genes of Helicobacter pylori associated with peptic ulcer in Japan. J. Clin. Microbiol. 43, 3906-3916.

Ye, D., and Blanke, S. R. (2000). Mutational analysis of the Helicobacter pylori vacuolating 
toxin amino terminus: identification of amino acids essential for cellular vacuolation. Infect. Immun. 68, 4354-4357.

Ye, D., and Blanke, S. R. (2002). Functional complementation reveals the importance of intermolecular monomer interactions for Helicobacter pylori VacA vacuolating activity. Mol. Microbiol. 43, 1243-1253.

Ye, D., Willhite, D. C., and Blanke, S. R. (1999). Identification of the minimal intracellular vacuolating domain of the Helicobacter pylori vacuolating toxin. J. Biol. Chem. 274, 9277-9282.
Yokoyama, K., Higashi, H., Ishikawa, S., Fujii, Y., Kondo, S., Kato, H., Azuma, T., Wada, A., Hirayama, T., Aburatani, H., and Hatakeyama, M. (2005). Functional antagonism between Helicobacter pylori CagA and vacuolating toxin $\operatorname{VacA}$ in control of the NFAT signaling pathway in gastric epithelial cells. Proc. Natl. Acad. Sci. U.S.A. 102, 9661-9666.

Yuan, J. P., Li, T., Chen, H. B., Li, Z. H., Yang, G. Z., Hu, B. Y., Shi, X. D., Tong, S. Q., Li, Y. X., and Guo, X. K. (2004). Analysis of gene expression profile in gastric cancer cells stimulated with Helicobacter pylori isogenic strains. J. Med. Microbiol. 53, 965-974.

Zheng, P. Y., and Jones, N. L. (2003) Helicobacter pylori strains expressing the vacuolating cytotoxin interrupt phagosome maturation in macrophages by recruiting and retaining TACO (coronin 1) protein. Cell Microbiol. 5, 25-40.

Conflict of Interest Statement: The authors declare that the research was conducted in the absence of any commercial or financial relationships that could be construed as a potential conflict of interest.
Received: 02 December 2011; accepted: 05 March 2012; published online: 27 March 2012.

Citation: Kim I-J and Blanke SR (2012)

Remodeling the host environment: modulation of the gastric epithelium by the Helicobacter pylori vacuolating toxin (VacA). Front. Cell. Inf. Microbio. 2:37. doi: 10.3389/fcimb.2012.00037

Copyright (c) 2012 Kim and Blanke. This is an open-access article distributed under the terms of the Creative Commons Attribution Non Commercial License, which permits non-commercial use, distribution, and reproduction in other forums, provided the original authors and source are credited. 